\title{
TAXOMETRICS CLASSIFICATION (HIERARCHICAL AND ORDINATION) OF AQUATIC AND SEMI- AQUATIC MOSSES: A PRELIMINARY MODEL TO BRYODIVERSITY MANAGEMENT
}

\author{
M.J. LOO ${ }^{1 *}$, T. A. DELVALLS CASILLAS ${ }^{1}$ and L. MARTIN DIAZ ${ }^{12}$ \\ ${ }^{1}$ UNESCO/UNITWIN/WiCop..Department of Physical Chemistry, Faculty of Marine and \\ Environmental Sciences, Universidad de Cádiz - Rio San Pedro Campus, 11510 Puerto Real, Cádiz, \\ SPAIN. \\ ${ }^{12}$ Instituto de Ciencias Marinas de Andalucía. CSIC. Rio San Pedro Campus, 11510 Puerto Real, \\ Cádiz, SPAIN.
}

\begin{abstract}
Bryodiversity is naturally serving the ecosystems sustainably. It serves the environments by preventing natural disaster (flooding), maintaining the quality of the water body and filter or treats the pollutants naturally. Efficient bryodiversity management is needed for environmental cost cutting and have a cost-effective management strategy. To achieve this, cluster and principal component analyses (PCA) were manipulated to produce the linkage distance between the OTUs and identify the important groups of characters, respectively. In return, it becomes a guideline for bryoflora and environmental managements. In this study, 23 OTUs and 156 characters were analyzed. The output from the reliability and item analysis showed that the data set is highly reliable (Cronbach's alpha $=0.9627$ ). From the cluster analysis, it showed that 5 clustered groups (manageable units) could be derived from the produced phenogram. This is based on the nearest neighbour amalgation rule and Euclidean distances. As for the principal component analysis, three factors were derived and explained $75.1064 \%$ of the variation with $56.0485 \%(\mathrm{PC} 1), 11.7346 \%(\mathrm{PC} 2)$ and $7.3233 \%$ (PC3), respectively. The ordination showed that 5 manageable units were derived from PC1 and 3 manageable units for PC2 and PC3, respectively. In conclusion, conservation should precede any biodiversity management plans.
\end{abstract}

Key words: aquatic mosses, semi-aquatic mosses, cluster analysis, principal component analysis (PCA), classification 


\section{INTRODUCTION}

Bryodiversity management is a new discipline in management science. Bryodiversity refers to the richness of bryophytes (mosses, liverworts and hornworts). Management signifies planning conservational strategy, organizing conservational plans, implementing organized conservational approach and controlling or sustaining the on-going of the implemented plan with the aim to conserve the nature (Raffield and Bingham 1994). Based on Stuessy (1990), biosystematics is crucial in understanding the biodiversity of a particular ecosystem. In this context the focus is on the richness of aquatic and semiaquatic mosses. Without knowing the richness, no conservation plan will be implemented and thus, floral extinction is highly potential.

In this study, aquatic and semi-aquatic mosses were studied phenetically to find out the rarity and commonness among the studied populations. This is very crucial in conservation where rare species should be urgently conserved and less threatened spesies should be sustained too. Cost-effective is the success key in any management activities (Raffield and Bingham 1994). Phenetic analysis (cluster analysis and principal component analysis) will statistically group species with the most similar characters together (Scotland and Carine 2000; Komosinki et al. 2001; and Aguilar et al. 2004) and forms few manageable units. Instead of over-consuming time and costs for few related or familiar species and neglecting other populations, managing clustered group will be the solution in the successful bryodiversity management.

This new approach aims for conservation and at the same time continues serving the needs of the ecosystem. In term of costs, no artificial flood mitigator and barrier, no water quality tester and no waste water contamination might be required if aquatic and semi-aquatic mosses are present in the natural habitats (Ando and Matsuo 1984; Frahm 1996; Welch 1948; Conrad 1935; Whitehouse and McAllister 1954; Ando 1957; Grout 1912; Coupal and Lalancette 1976).

\section{MATERIALS AND METHODS}

\section{Moss material and characterization}

Twenty-three species or operational taxonomic units were selected and 156 characters with different level of character states (Table 1) were chosen for numerical classification. Further phenetic methodology referred to Stuessy (1990), Stotler and Stotler (2000), Frahm (2003), Smith (1978), Holmes (1998), Tsai et al. (2002); and Yamagishi et al. (2005). The main sources for analyses were morphological and anatomical data: vegetative (gametophyte) and reproductive (sporophyte) components. Both taxonomic sources were measured quantitatively and qualitatively.

Table 1. Characters and character states for the taxometric analyses

(1)Plant size(0-small,1-big/large,2-others); (2)Plant habitat and submergence (0-semi-aquatic,1aquatic,2-not submerged,3-sometimes partly submerged,4-occasionally submerged,5-others); (3)Plant colour(0-greenish to blackish and rarely whitish,1-others); (4)Ephemerality of plant(0-no,1-yes,2others); (5)Plant growth form(0-acrocarpous, 1-pleurocarpous,2-others); (6)Plant covered by glaucous 


\section{Table 1. Continued}

or bluish(0-no,1-yes,2-others); (7)Plant: prostate to erect(0-no,1-yes,2-others); (8)Plant branching form(0-simple to pinnately branched,1-others); (9)Rarity of plant( 0 -rare to common,1-others); (10)Plant: terete or julaceous form(0-no,1-yes,2-others); (11)Plant: means of asexual reproduction(0without,1-with,2-without or with,3-others); (12)Plant: coarseness(0-not coarse,1-coarse,2-others); (13)Plant with flattened shoots(0-no,1-yes,2-others); (14)Autoicous (autoecious)( 0 -without archegonia and antheridia in separate influorescences,1-with archegonia and antheridia in separate influorescences,2-others); (15)Plant with innovative branches beneath inflorescences(0-no,1-rare,2often,3-others); (16)Plant: more than 5mm(0-no,1-yes,2-others); (17)Rhizoids(0-obvious/with rhizodal tubers, 1 -not obvious,2-others; (18)Leaves unbordered by row of cells( 0 -no,1-yes,2-others); (19)Leaf bordered by(0-elongate cells, 1 -smooth cells,2-others); (20)Leaf sheathing(0-rarely, 1-often,2others); (21)Leaf costa ending below the apex to excurrent(0-no,1-yes,2-others); (22)Leaf without hair-points(0-no,1-yes,2-others); (23)Leaf hair-points(0-hyaline,1-others); (24)Leaves all of one kind(0-no,1-yes,2-others); (25)Leaves direction(0-homomallous, 1 -others); (26)Leaves arrangement(0attached all around the stem,1-attached in two rows on opposite sides of the stem (distichous),2others); (27)Leaf lamina(0-conspicious, 1 -others); (28)Leaf lamina unistratose(0-no,1-yes,2-others); (29)Leaf layer(0-unistratose,1-multistratose,2-unistratose to multistratose,3-others); (30)Leaves inconspiciously ranked(0-no,1-yes,2-others); (31)Leaves apex(0-ovate to spatulate,1-others); (32)Leaves tip ( 0 -acuminate to acute (awned), 1-others); (33)Leaves( 0 -various, 1 -undulate, 2 -straight or straight when dry,3-plicate or deeply plicate,4-plicate or not,5-concave,6-others); (34)Leaf (dorsal view) (0-keeled or flat, 1-others); (35)Leaves position(0-at extreme apex, 1 -others); (36)Leaf alteration(0little altered when dry, 1 -others); (37)Adaxial surface of the leaf costa( 0 -without lamellae or filaments, 1with lamellae or filaments,2-broadly channeled or flat,3-others); (38)Leaf without cancellinae(0-no,1yes,2-others); (39)Spreading leaves(0-without,1-with,2-with and wide,3-others); (40)Differentiation of branch and stem leaves(0-strongly,1-weakly/scarcely,2-others); (41)Apical cells of branch leaves(0about $1 / 2$ length of those at midleaf,1-scarcely shorter than those at midleaf,2-others); (42)Leaf bases(0-without cancellinae,1-with cancellinae,2-others); (43)Leaf base with appear split(0-no,1yes,2-others); (44)Sheathing base of leaves(0-without,1-rarely,2-with,3-others); (45)Concave leaf bases( 0 -not concave, 1 -not concave and with a narrow insertion,2-with,3-others); (46)Leaf longer than $1 \mathrm{~mm}$ (0-no,1-yes,2-others); (47)Leaf cross-section(0-recurved only on one side,1-plane to recurved,2recurved to revolute,3-revolute,4-others); (48)Leaf bases never or gradually expanded(0-no,1-yes,2others); (49)Propagula in leaf apices(0-without,1-with,2-others); (50)Leaf apices at extreme apex(0margins entire or papillose-crenulate,1-others); (51)Leaf apices(0-acuminate to bluntly acute,1cuspidate,2-cuspidate to piliferous,3-without piliferous or aristate (awn),4-with piliferous or aristate (awn),5-others); (52)Channeled leaf apices(0-no,1-yes,2-others); (53)Leaf cell diametry(0isodiametric,1-more or less isodiametric,2-others); (54)Leaf cell surface(0-flat, smooth and papillose,1smooth, bulging or prorulose,2-smooth,3-papillose or prorulose,4-smooth and papillose,5-flat,6papillose (uni to pluri) or prorulose,7-rarely with minute cuticular roughenings,8-others); (55)Leaf cell type(0-one type,1-others); (56)Leaf cell colour(0-green,1-others); (57)Size of leaf cells(0-shorts,1longs,2-others); (58)Relative size of leaf cells(zero.1(-2):1,one.above about 3:1 or longer,two.4:1 or less,three.1-4(-5), four.more than 10:1,five.(3-)4:1 or longer,six.others); (59)Relative size of upper leaf cells(zero. more than 5:1, one. 2-6:1,two.others); (60)Leaf cell papillose(0-no,1-pluripapillose,2-closely set, simple to branched papillae/simple to branched papillae,3-unipapollose to pluripapillose,4-with papillae stellate from a stipitate base to C-shaped,5-others); (61)Leaf cells in obvious rows(0-no,1yes,2-others); (62)Leaf cell shape(0-long-hexagonal,1-short-rectangular to linear,2-conic, clavate or branched and rarely C-shaped,3-rounded to quadrate,4-linear,5-merely rounded and not stellate,6- 


\section{Table 1. Continued}

long, linear and hexagonal,7-rectangular,8-rectangular to long-hexagonal,9-others) ; (63)Upper leaf cells(0-smooth or with low and indistinct papillae,1-smooth,2-firm-walled and short-oblong to rhombic,3- prorulose,4-densely pluripapillose with C-shaped papillae,5-others); (64)Basal leaf cells(0usually without thickened transverse walls, 1 -others); (65)Papillose over the lumina or prorulose in leaf cells(0-no,1-yes,2-only papillose over the lumina,3-others);(66)Mid leaf cells of stem leaf(0-40-120 $\mu \mathrm{m}$ long,1-others);(67)Branch and stem leaves scarcely differentiated(0-no,1-yes,2-others);(68)Leaf margin(0-single teeth or entire,1-entire,2-toothed,3-abruptly serrate at the shoulder,4-entire and denticulate,5-serrate margins whose teeth are often reflexed,6-entire or papillose-crenulate,7-with paired teeth,8-others);(69)Numbers of leaf margin(0-single,1-double,2-two to multilayered,3others);(70)Near midleaf or below recurved to revolute(0-no,1-yes,2-others);(71)Upper leaf margins plane to revolute (with cells undifferentiated or paler than median cells)(0-no,1-yes,2others);(72)Stomates(0-absent,1-present,2-others);(73)Leaf costa(0-without a costa or costa short and double, double or single with 2-3 lateral spurs,1-single,2-distinct throughout,3-others);(74)Adaxial surface of leaf along costa(0-broadly channelled or flat,1-others);(75)Single leaf costa to at least midleaf(0-yes,1-others);(76)Apical of leaf costa( 0 -subpercurrent,1-bluntly excurrent,2-excurrent to ending in the cusp,3-others);(77) Transverse section of leaf costa(0-2 stereid bands, 1 -single and dorsal stereid band,2-differentiated stereid bands,3-others);(78)Both dorsal and ventral stereid bands present (0-no,1-yes,2-others); (79)Cells of abaxial surface of costa( 0 -oblong and elongate, 1 -quadrate to short-oblong,2-others);(80)Dorsal part of leaf costa(0-smooth or toothed at back (ridged),1-not ridged,2-others);(81)Size of leaf costa(0-narrow or much narrower,1-wide or broad,2others);(82)Lamellae or filaments on the adaxial surface of the costa(0-without,1-with,2others);(83)Ventral costal epidermis(0-absent,1-present,2-others);(84)Cells of adaxial (upper) surface of costa similar to or smaller than laminal cells in transverse section(0-no,1-yes,2-others);(85)Costa more than $100 \mu \mathrm{m}$ wide at base( 0 -no,1-yes,2-others); (86)Costa ending in the leaf apex(0-no,1-yes,2others);(87)Costa ending below the apex to excurrent(0-no,1-yes,2-others);(88)Costa ending in a spine(0-no,1-yes,2-others);(89)Costa occupying less than $1 / 4$ the leaf base(0-no,1-yes,2others);(90)Axilliary hairs(0-hyaline,1-brown,2-others);(91)Basal cells of axilliary hairs(0-slender,1others);(92)Alar cells(0-scarcely differentiated,1-inflated in well marked groups,2-not at all inflated,3alar group not extending more than $20-40 \%$ up leaf,4-others);(93)Stem paraphyllia(0-no,1-no or lacking,2-abundant and filamentous,3-others);(94)Stem paraphyllia foliose(0-no,1-yes,2-others); (95)Foliate stem (0-sometimes complanate, 1 -foliate throughout and without rhizome-like connections between erect stems,2-symmetrical,3-sometimes flattened,4-others);(96)Stem form(0-erect,1occasionally branched beneath influrouscences,2-others);(97)Stem branching( 0 -not branched,1mostly prostrate with lateral branches,2-prostrate with erect branches bearing terminal sporophytes (cladocarpous),3-branching various (e.g. complanate-foliate, flattened-foliate, prostrate with lateral branches and ranches curved downwards),4-others);(98)Stem ranked leaves(0-without,1-with,2others);(99)Stem: central strand(0-absent,1-present,2-others);(100)Stem: hyalodermis(0-absent,1present,2-others);(101)Stem abundance(0-sparse to abundant,1-others);(102)Stem sclerodermis(0clearly differentiated,1-not or weakly developed,2-others); (103)Stem size(0-up to $2.7 \mathrm{~mm}$ long,1others); (104)Stem epidermal cells(0-small,1-big/large,2-others); (105)Stems round in transverse section(0-no,1-yes,2-others); (106)Sporophytes(0-various types,1-terminal,2-not clustered,3-lateral,4others);(107)Size of capsule(0-small,1-big/large,2-others);(108)Capsule projection(0-long-exserted,1exserted,2-others); (109)Capsule symmetry(0-symmetric,1-asymmetric,2-others); (110)Capsule(0operculate or cleistocarpous, 1-others); (111)Capsule: valvate(0-never,1-always,2-others); (112)Capsule growth form(0-erect or straight,1-inclined to pendulous,2-horizontal to pendulous,3-never furrowed 
Table 1. Continued

or strumose,4-globose and rugulose to furrowed when dry,5-horizontal or pendulous,6others);(113)Neck of capsule(0-short and inconspicious/inconspicuous,1-others);(114)Surface of capsule(0-smooth,1-smooth or furrowed,2-others);(115)Capsule narrower than urn(0-no,1-yes,2others);(116)Position of capsule(0-distinctly terminal/terminal,1-others);(117)Shape of capsule(0cylindric to oval,1-others);(118)Capsule longer than $1 \mathrm{~mm}(0$-no,1-yes,2-others);(119)Capsule apex and unlobed at base(0-no,1-yes,2-others);(120)Calyptrae(0-cucullate,1-others);(121)Calyptrae: plicate(0-no,1-yes,2-others);(122)Covering of calyptrae( 0 -covering only operculum,1-covering only operculum and capsule apex,2-others);(123)Calyptrae unlobed at base(0-no,1-yes,2-others);(124)Size of calyptrae(0-small,1-large/big,2-others);(125)Peristome(0-absent,1-present,2-present with papillose,3-others);(126)Number of peristome(0-single,1-single or absent,2-single or double,3double,4-others);(127)Peristome teeths(0-16,1-with teeth united in a high or rarely low,2others);(128)Peristome state(0-not reflexed,1-spirally twisted above,2-with tubular basal membrane ,3-others);(129)Development of peristome(0-weakly developed,1-better developed,2-strongly developed,3-others);(130)Basal membrane of endostome(0-keeled,1-others);(131)Segments of endostome(0-keeled and perforate,1-others);(132)Endostome with cilia(0-no,1-yes,2others);(133)Exostome(0-without or free of, 1-with,2-others);(134)Operculum(0-conic to apiculate, 1others);(135)Projection of seta(0-exserted,1-others);(136)Size of seta(0-longer than $2 \mathrm{~mm}$,1-others);(1 37)Perichaetial position(0-terminal,1-usually low and simple to bifid,2-others);(138)Perichaetia with papillae(0-no,1-yes,2-absent to large,3-others);(139)Perichaetial surface(0-not scablike,1-scablike,2-ot hers);(140)Perichaetial leaves (bract)(0-slightly or not differentiated,1-not differentiated,2-less differentiated,3-others);(141)Shape of bract(0-never long awned,1-others);(142)Propagula cup (0absent,1-present,2-others);(143)Propagula(0-absent,1-present,2-with or without,3-sometimes present,4-never on leaf apices but sometimes elsewhere on leaves or in axils,5-others);(144)Axillary propagula(0-without,1-with,2-others);(145)Cells without nodulose-waxy walls(0-no,1-yes,2others);(146)Cell characteristics(0-smooth, lax, thin-walled and hexagonal to rhombic,1others);(147)Cells of old plants without colour change to bluish-green(0-no,1-yes,2-others);(148)Cell walls not thickened on abaxial side(0-no,1-yes,2-others);(149)Angular cells(0-not opaque,1others);(150)End walls of basal cells not thickened(0-no,1-yes,2-others);(151)Hyaline basal cells (if present)(0-extending equal to costa,1-others);(152)Laminal cells surface view(0-obscure, 1 -welldefined,2-others); (153)Basal laminal cells(0-differentiated, hyaline and elongated, 1-little differentiated, green and short-rectangular,2-others);(154)Tomentum (if present)(0-restricted to extreme base of

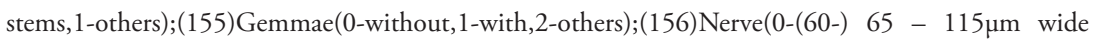
near base, 1 -others).

\section{Data analysis}

Two analyses: cluster analysis (depicting similarities among OTUs) (Madeira et al. 1999; Ferguson et al. 2000; Sharma et al. 2004) and principal component analysis (PCA) (non-hierarchical relationships among OTUs) (McNulty 2004) were chosen and performed on the matrix data (Table 2-11). For cluster analysis, single linkage amalgation rule and Euclidean distances measure were manipulated for classification. STATISTICA 6.0 (by StatSoft, Inc. 2001) was utilized in this taxometric study (Mazak and Groves, 2006). Further numerical taxonomic methodology followed Luna et al. (2000); Romero et al. (2000); and Kim et al. (2003). 


\section{Data validation}

Reliability and item analysis was performed to measure the overall representation of the data analyzed and degree of bias. This test was run with STATISTICA 6.0 (by StatSoft, Inc, 2001).

\section{RESULTS AND DISCUSSIONS}

The output from the reliability and item analysis showed that the data set is highly reliable (Cronbach's alpha $=0.9627$ ). This means that more than $96 \%$ of the data analyzed were true score variability and reflecting the real situation. This value is higher than the standardized alpha (0.9612).

The character states (156 characters examined) for 23 OTUs (Table 2-11) were analyzed and produced 22 nodes for classification.

Table 2. Matrix table showing the character states (156 characters) for the 23 OTUs of aquatic and semi-aquatic mosses

\begin{tabular}{|c|c|c|c|c|c|c|c|c|c|c|c|c|c|c|c|c|c|c|}
\hline Operational Taxonomic Unit (OTU) & 1 & 2 & 3 & 4 & 5 & 6 & 7 & 8 & 9 & 10 & 11 & 12 & 13 & 14 & 15 & 16 & 17 & 18 \\
\hline Barbula bolleana (Müll. Hal.) Broth. & 1 & 0 & 0 & 0 & 0 & 0 & 1 & 0 & 0 & 2 & 3 & 2 & 2 & 2 & 3 & 2 & 1 & 1 \\
\hline Bryum caespiticium Hedw. & 1 & 2 & 1 & 0 & 0 & 0 & 1 & 0 & 0 & 0 & 2 & 1 & 0 & 2 & 3 & 2 & 1 & 1 \\
\hline $\begin{array}{l}\text { Bryum pseudotriquetrum (Hedw.) P. } \\
\text { Gaertn., B. Mey \& Scherb. }\end{array}$ & 1 & 3 & 1 & 0 & 0 & 0 & 1 & 0 & 0 & 0 & 2 & 1 & 0 & 2 & 3 & 2 & 1 & 1 \\
\hline Cratoneuron filicinum (Hedw.) Spruce & 2 & 0 & 1 & 2 & 2 & 2 & 1 & 0 & 1 & 2 & 3 & 2 & 2 & 2 & 3 & 2 & 2 & 2 \\
\hline Didymodon tophaceus (Brid.) Lisa & 1 & 0 & 0 & 0 & 0 & 0 & 1 & 0 & 0 & 2 & 3 & 2 & 2 & 2 & 3 & 2 & 1 & 1 \\
\hline $\begin{array}{l}\text { Eucladium verticillatum (Brid.) Bruch \& } \\
\text { Schimp. }\end{array}$ & 1 & 0 & 0 & 0 & 0 & 0 & 1 & 0 & 0 & 2 & 2 & 2 & 2 & 2 & 3 & 2 & 1 & 0 \\
\hline Eurhynchium speciosum (Brid.) Jur. & 1 & 0 & 0 & 0 & 1 & 2 & 0 & 1 & 0 & 2 & 3 & 2 & 2 & 2 & 3 & 2 & 2 & 0 \\
\hline $\begin{array}{l}\text { Eurhynchium hians (Hedw.) Sande Lac. } \\
\text { var. hians }\end{array}$ & 1 & 0 & 0 & 0 & 1 & 2 & 0 & 1 & 0 & 2 & 3 & 2 & 2 & 2 & 3 & 2 & 2 & 0 \\
\hline $\begin{array}{l}\text { Fissidens crassipes subsp. warnstorfii (M. } \\
\text { Fleisch.) Brugg.-Nann. }\end{array}$ & 2 & 0 & 1 & 2 & 2 & 2 & 2 & 1 & 1 & 2 & 3 & 2 & 2 & 2 & 3 & 2 & 2 & 2 \\
\hline Fissidens grandifrons Brid. & 2 & 4 & 1 & 2 & 2 & 2 & 2 & 1 & 1 & 2 & 3 & 2 & 2 & 2 & 3 & 2 & 2 & 2 \\
\hline Fontinalis antipyretica Hedw. & 2 & 1 & 1 & 2 & 1 & 2 & 2 & 1 & 1 & 2 & 3 & 2 & 2 & 2 & 3 & 2 & 2 & 2 \\
\hline Fontinalis duriaei Schimp. & 2 & 4 & 1 & 2 & 1 & 2 & 2 & 1 & 1 & 2 & 3 & 2 & 2 & 2 & 3 & 2 & 2 & 2 \\
\hline $\begin{array}{l}\text { Gymnostomum calcareum Nees \& } \\
\text { Hornsch. }\end{array}$ & 1 & 0 & 0 & 2 & 0 & 0 & 1 & 0 & 0 & 2 & 2 & 2 & 2 & 2 & 3 & 2 & 1 & 0 \\
\hline Hygroamblystegium tenax (Hedw.) Jenn. & 1 & 1 & 0 & 0 & 1 & 2 & 1 & 0 & 0 & 2 & 3 & 1 & 2 & 2 & 3 & 2 & 2 & 1 \\
\hline $\begin{array}{l}\text { Hymenostylium recurvirostrum (Hedw.) } \\
\text { Dixon }\end{array}$ & 2 & 0 & 1 & 2 & 2 & 2 & 2 & 1 & 1 & 2 & 3 & 2 & 2 & 2 & 3 & 2 & 2 & 2 \\
\hline Leptodictyum humile (P. Beauv.) Ochyra & 2 & 0 & 0 & 0 & 1 & 2 & 1 & 0 & 0 & 2 & 3 & 2 & 1 & 1 & 3 & 2 & 2 & 0 \\
\hline Leptodictyum riparium (Hedw.) Warnst. & 2 & 0 & 0 & 0 & 1 & 2 & 1 & 0 & 0 & 2 & 3 & 2 & 1 & 1 & 3 & 2 & 2 & 0 \\
\hline Palustriella commutata (Hedw.) Ochyra & 2 & 0 & 0 & 2 & 2 & 2 & 1 & 0 & 1 & 2 & 3 & 2 & 2 & 2 & 3 & 2 & 2 & 2 \\
\hline Philonotis fontana (Hedw.) Brid. & 1 & 4 & 0 & 0 & 0 & 0 & 1 & 0 & 0 & 2 & 3 & 2 & 2 & 2 & 2 & 2 & 1 & 2 \\
\hline Platyhypnidium riparioides (Hedw.) Dixon & 1 & 1 & 0 & 0 & 1 & 2 & 1 & 0 & 0 & 2 & 3 & 2 & 2 & 2 & 3 & 2 & 2 & 0 \\
\hline Pohlia melanodon (Brid.) A.J. Shaw & 1 & 0 & 0 & 0 & 0 & 0 & 1 & 0 & 0 & 0 & 3 & 1 & 2 & 2 & 3 & 1 & 1 & 1 \\
\hline $\begin{array}{l}\text { Pohlia wahlenbergii (F. Weber \& D. } \\
\text { Mohr) A.L. Andrews }\end{array}$ & 1 & 0 & 0 & 0 & 0 & 0 & 1 & 0 & 0 & 0 & 3 & 1 & 2 & 2 & 3 & 1 & 1 & 1 \\
\hline $\begin{array}{l}\text { Tortula marginata (Bruch \& Schimp.) } \\
\text { Spruce }\end{array}$ & 1 & 0 & 0 & 0 & 0 & 0 & 1 & 0 & 0 & 2 & 2 & 2 & 2 & 2 & 3 & 2 & 0 & 0 \\
\hline
\end{tabular}


Table 3. Matrix table showing the character states (156 characters) for the 23 OTUs of aquatic and semi-aquatic mosses.

\begin{tabular}{|c|c|c|c|c|c|c|c|c|c|c|c|c|c|c|c|c|c|c|}
\hline Operational Taxonomic Unit (OTU) & 19 & 20 & 21 & 22 & 23 & 24 & 25 & 26 & 27 & 28 & 29 & 30 & 31 & 32 & 33 & 34 & 35 & 36 \\
\hline Barbula bolleana (Müll. Hal.) Broth. & 2 & 2 & 2 & 1 & 1 & 1 & 1 & 0 & 0 & 2 & 2 & 1 & 1 & 1 & 0 & 1 & 0 & 1 \\
\hline Bryum caespiticium Hedw. & 0 & 2 & 1 & 1 & 1 & 1 & 2 & 0 & 0 & 2 & 3 & 2 & 0 & 0 & 0 & 1 & 1 & 1 \\
\hline $\begin{array}{l}\text { Bryum pseudotriquetrum (Hedw.) P. } \\
\text { Gaertn., B. Mey \& Scherb. }\end{array}$ & 0 & 2 & 1 & 1 & 1 & 1 & 2 & 0 & 0 & 2 & 3 & 2 & 0 & 0 & 0 & 1 & 1 & 1 \\
\hline Cratoneuron filicinum (Hedw.) Spruce & 2 & 2 & 2 & 2 & 1 & 2 & 1 & 0 & 1 & 2 & 3 & 2 & 1 & 1 & 5 & 1 & 1 & 1 \\
\hline Didymodon tophaceus (Brid.) Lisa & 2 & 2 & 2 & 0 & 1 & 1 & 1 & 0 & 0 & 2 & 1 & 1 & 1 & 1 & 0 & 1 & 0 & 1 \\
\hline $\begin{array}{l}\text { Eucladium verticillatum (Brid.) Bruch \& } \\
\text { Schimp. }\end{array}$ & 2 & 2 & 2 & 1 & 1 & 1 & 1 & 0 & 0 & 2 & 0 & 2 & 1 & 1 & 0 & 1 & 1 & 1 \\
\hline Eurhynchium speciosum (Brid.) Jur. & 0 & 2 & 2 & 1 & 1 & 1 & 2 & 0 & 0 & 2 & 3 & 2 & 1 & 1 & 3 & 1 & 1 & 1 \\
\hline $\begin{array}{l}\text { Eurhynchium hians (Hedw.) Sande Lac. } \\
\text { var. hians }\end{array}$ & 0 & 2 & 2 & 1 & 1 & 1 & 2 & 0 & 0 & 2 & 3 & 2 & 1 & 1 & 4 & 1 & 1 & 1 \\
\hline $\begin{array}{l}\text { Fissidens crassipes subsp. warnstorfii (M. } \\
\text { Fleisch.) Brugg.-Nann. }\end{array}$ & 2 & 2 & 2 & 2 & 1 & 2 & 1 & 1 & 1 & 2 & 3 & 2 & 1 & 1 & 6 & 1 & 1 & 1 \\
\hline Fissidens grandifrons Brid. & 2 & 2 & 2 & 2 & 1 & 2 & 1 & 1 & 1 & 2 & 3 & 2 & 1 & 1 & 6 & 1 & 1 & 1 \\
\hline Fontinalis antipyretica Hedw. & 2 & 2 & 2 & 2 & 1 & 2 & 1 & 0 & 1 & 1 & 3 & 2 & 1 & 1 & 6 & 0 & 1 & 1 \\
\hline Fontinalis duriaei Schimp. & 2 & 2 & 2 & 2 & 1 & 2 & 1 & 0 & 1 & 1 & 3 & 2 & 1 & 1 & 6 & 0 & 1 & 1 \\
\hline $\begin{array}{l}\text { Gymnostomum calcareum Nees \& } \\
\text { Hornsch. }\end{array}$ & 2 & 2 & 2 & 1 & 1 & 1 & 1 & 0 & 0 & 2 & 0 & 2 & 1 & 1 & 0 & 1 & 0 & 1 \\
\hline Hygroamblystegium tenax (Hedw.) Jenn. & 0 & 2 & 2 & 1 & 1 & 1 & 1 & 0 & 0 & 2 & 3 & 2 & 1 & 1 & 0 & 1 & 0 & 1 \\
\hline $\begin{array}{l}\text { Hymenostylium recurvirostrum (Hedw.) } \\
\text { Dixon }\end{array}$ & 2 & 2 & 2 & 2 & 1 & 2 & 1 & 0 & 1 & 2 & 3 & 2 & 1 & 1 & 6 & 1 & 0 & 1 \\
\hline Leptodictyum humile (P. Beauv.) Ochyra & 2 & 2 & 1 & 1 & 2 & 1 & 1 & 0 & 0 & 2 & 3 & 2 & 1 & 1 & 4 & 1 & 1 & 1 \\
\hline Leptodictyum riparium (Hedw.) Warnst. & 2 & 2 & 1 & 1 & 2 & 1 & 1 & 0 & 0 & 2 & 3 & 2 & 1 & 1 & 4 & 1 & 1 & 1 \\
\hline Palustriella commutata (Hedw.) Ochyra & 2 & 2 & 2 & 2 & 1 & 2 & 1 & 0 & 1 & 2 & 3 & 2 & 1 & 1 & 3 & 1 & 1 & 1 \\
\hline Philonotis fontana (Hedw.) Brid. & 2 & 0 & 2 & 0 & 1 & 1 & 1 & 0 & 0 & 2 & 0 & 1 & 1 & 1 & 2 & 1 & 1 & 1 \\
\hline Platyhypnidium riparioides (Hedw.) Dixon & 2 & 2 & 1 & 2 & 1 & 1 & 1 & 0 & 0 & 2 & 3 & 2 & 1 & 1 & 4 & 1 & 1 & 1 \\
\hline Pohlia melanodon (Brid.) A.J. Shaw & 2 & 2 & 2 & 1 & 1 & 1 & 1 & 0 & 0 & 2 & 3 & 1 & 1 & 1 & 6 & 1 & 1 & 0 \\
\hline $\begin{array}{l}\text { Pohlia wahlenbergii (F. Weber \& D. Mohr) } \\
\text { A.L. Andrews }\end{array}$ & 2 & 2 & 2 & 1 & 1 & 1 & 1 & 0 & 0 & 2 & 3 & 1 & 1 & 1 & 6 & 1 & 1 & 0 \\
\hline $\begin{array}{l}\text { Tortula marginata (Bruch \& Schimp.) } \\
\text { Spruce }\end{array}$ & 1 & 2 & 2 & 0 & 0 & 1 & 1 & 0 & 0 & 2 & 0 & 2 & 1 & 1 & 6 & 1 & 1 & 1 \\
\hline
\end{tabular}

Table 4. Matrix table showing the character states (156 characters) for the 23 OTUs of aquatic and semi-aquatic mosses.

\begin{tabular}{|c|c|c|c|c|c|c|c|c|c|c|c|c|c|c|c|c|c|c|}
\hline Operational Taxonomic Unit (OTU) & 37 & 38 & 39 & 40 & 41 & 42 & 43 & 44 & 45 & 46 & 47 & 48 & 49 & 50 & 51 & 52 & 53 & 54 \\
\hline Barbula bolleana (Müll. Hal.) Broth. & 0 & 2 & 3 & 2 & 2 & 1 & 2 & 0 & 3 & 2 & 1 & 1 & 0 & 0 & 5 & 2 & 0 & 0 \\
\hline Bryum caespiticium Hedw. & 1 & 2 & 3 & 2 & 2 & 2 & 2 & 0 & 3 & 2 & 1 & 1 & 2 & 1 & 5 & 2 & 2 & 0 \\
\hline $\begin{array}{l}\text { Bryum pseudotriquetrum (Hedw.) P. } \\
\text { Gaertn., B. Mey \& Scherb. }\end{array}$ & 1 & 2 & 3 & 2 & 2 & 2 & 2 & 0 & 3 & 2 & 1 & 1 & 2 & 1 & 5 & 2 & 2 & 0 \\
\hline Cratoneuron filicinum (Hedw.) Spruce & 0 & 2 & 3 & 2 & 2 & 2 & 2 & 3 & 3 & 2 & 4 & 2 & 2 & 1 & 5 & 2 & 2 & 8 \\
\hline Didymodon tophaceus (Brid.) Lisa & 2 & 1 & 3 & 2 & 2 & 2 & 2 & 0 & 3 & 2 & 1 & 1 & 0 & 0 & 5 & 2 & 2 & 0 \\
\hline $\begin{array}{l}\text { Eucladium verticillatum (Brid.) Bruch \& } \\
\text { Schimp. }\end{array}$ & 3 & 1 & 3 & 2 & 2 & 2 & 2 & 0 & 3 & 2 & 1 & 2 & 2 & 1 & 5 & 2 & 2 & 6 \\
\hline Eurhynchium speciosum (Brid.) Jur. & 3 & 2 & 1 & 0 & 0 & 2 & 2 & 0 & 0 & 2 & 1 & 2 & 2 & 1 & 0 & 2 & 2 & 2 \\
\hline $\begin{array}{l}\text { Eurhynchium hians (Hedw.) Sande Lac. } \\
\text { var. hians }\end{array}$ & 3 & 2 & 1 & 0 & 0 & 2 & 2 & 0 & 0 & 2 & 1 & 2 & 2 & 1 & 0 & 2 & 2 & 2 \\
\hline
\end{tabular}


Table 4. Continued

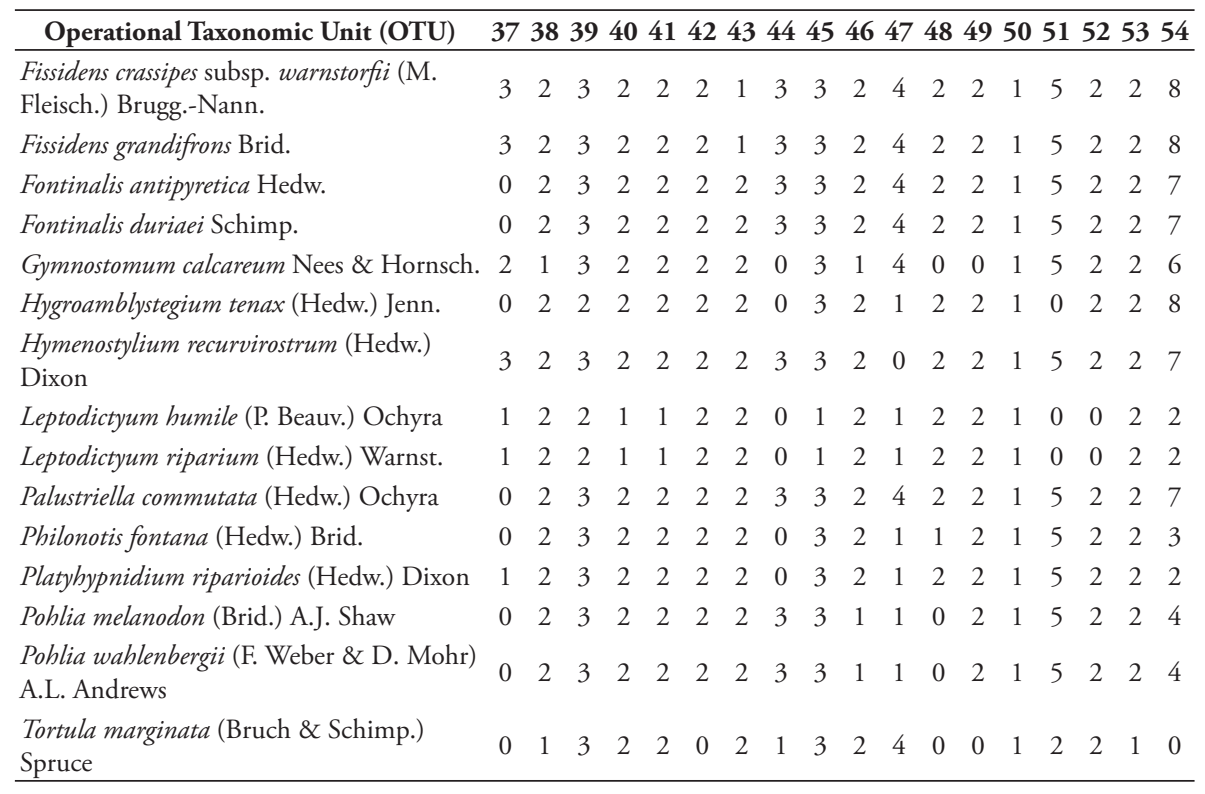

Table 5. Matrix table showing the character states (156 characters) for the 23 OTUs of aquatic and semi-aquatic mosses.

\begin{tabular}{|c|c|c|c|c|c|c|c|c|c|c|c|c|c|c|c|c|c|c|}
\hline Operational Taxonomic Unit (OTU) & 55 & 56 & 57 & 58 & 59 & 60 & 61 & 62 & 63 & 64 & 65 & 66 & 67 & 68 & 697 & 707 & 71 & 72 \\
\hline Barbula bolleana (Müll. Hal.) Broth. & 0 & 0 & 0 & 0 & 1 & 2 & 3 & 5 & 1 & 2 & 1 & 2 & 0 & 3 & 2 & 2 & 2 & 3 \\
\hline Bryum caespiticium Hedw. & 0 & 0 & 2 & 1 & 2 & 5 & 0 & 0 & 0 & 1 & 3 & 1 & 2 & 1 & 0 & 2 & 2 & 1 \\
\hline $\begin{array}{l}\text { Bryum pseudotriquetrum (Hedw.) P. } \\
\text { Gaertn., B. Mey \& Scherb. }\end{array}$ & 0 & 0 & 2 & 1 & 2 & 5 & 0 & 0 & 0 & 1 & 3 & 1 & 2 & 1 & 0 & 2 & 2 & 1 \\
\hline Cratoneuron filicinum (Hedw.) Spruce & 0 & 0 & 2 & 6 & 2 & 5 & 2 & 9 & 5 & 2 & 3 & 2 & 2 & 8 & 3 & 2 & 2 & 2 \\
\hline Didymodon tophaceus (Brid.) Lisa & 0 & 0 & 0 & 3 & 2 & 2 & 2 & 2 & 5 & 0 & 2 & 1 & 2 & 0 & 3 & 2 & 2 & 2 \\
\hline $\begin{array}{l}\text { Eucladium verticillatum (Brid.) Bruch \& } \\
\text { Schimp. }\end{array}$ & 0 & 0 & 2 & 6 & 2 & 3 & 2 & 3 & 5 & 1 & 1 & 1 & 2 & 0 & 3 & 2 & 2 & 2 \\
\hline Eurhynchium speciosum (Brid.) Jur. & 0 & 0 & 2 & 4 & 0 & 2 & 4 & 5 & 1 & 1 & 3 & 1 & 2 & 5 & 3 & 2 & 2 & 2 \\
\hline $\begin{array}{l}\text { Eurhynchium hians (Hedw.) Sande Lac. } \\
\text { var. hians }\end{array}$ & 0 & 0 & 2 & 4 & 0 & 2 & 4 & 5 & 1 & 1 & 3 & 1 & 2 & 5 & 3 & 2 & 2 & 2 \\
\hline $\begin{array}{l}\text { Fissidens crassipes subsp. warnstorfii (M. } \\
\text { Fleisch.) Brugg.-Nann. }\end{array}$ & 0 & 0 & 2 & 6 & 2 & 5 & 2 & 9 & 5 & 1 & 3 & 1 & 2 & 8 & 3 & 2 & 2 & 2 \\
\hline Fissidens grandifrons Brid. & 0 & 0 & 2 & 6 & 2 & 5 & 2 & 9 & 5 & 1 & 3 & 1 & 2 & 8 & 3 & 2 & 2 & 2 \\
\hline Fontinalis antipyretica Hedw. & 0 & 0 & 2 & 6 & 2 & 5 & 2 & 9 & 1 & 1 & 3 & 1 & 2 & 1 & 3 & 2 & 2 & 2 \\
\hline Fontinalis duriaei Schimp. & 0 & 0 & 2 & 6 & 2 & 5 & 2 & 9 & 1 & 1 & 3 & 1 & 2 & 1 & 3 & 2 & 2 & 2 \\
\hline Gymnostomum calcareum Nees \& Hornsch. & 0 & 0 & 2 & 3 & 2 & 2 & 2 & 5 & 5 & 0 & 1 & 1 & 2 & 0 & 3 & 2 & 2 & 2 \\
\hline Hygroamblystegium tenax (Hedw.) Jenn. & 0 & 0 & 2 & 6 & 0 & 5 & 2 & 9 & 2 & 1 & 2 & 1 & 2 & 5 & 3 & 2 & 2 & 2 \\
\hline $\begin{array}{l}\text { Hymenostylium recurvirostrum (Hedw.) } \\
\text { Dixon }\end{array}$ & 0 & 0 & 2 & 6 & 2 & 1 & 2 & 9 & 5 & 1 & 3 & 1 & 2 & 6 & 3 & 1 & 2 & 2 \\
\hline Leptodictyum humile (P. Beauv.) Ochyra & 0 & 0 & 1 & 4 & 0 & 5 & 2 & 6 & 5 & 1 & 2 & 0 & 1 & 4 & 2 & 2 & 2 & 2 \\
\hline Leptodictyum riparium (Hedw.) Warnst. & 0 & 0 & 1 & 4 & 0 & 5 & 2 & 6 & 5 & 1 & 2 & 0 & 1 & 4 & 2 & 2 & 2 & 2 \\
\hline
\end{tabular}


Table 5. Continued

\begin{tabular}{|c|c|c|c|c|c|c|c|c|c|c|c|c|c|c|c|c|c|c|}
\hline Operational Taxonomic Unit (OTU) & 55 & 56 & 57 & 58 & 59 & 60 & 61 & 62 & 63 & 64 & 65 & 66 & 67 & 68 & 69 & 70 & 71 & 72 \\
\hline Palustriella commutata (Hedw.) Ochyra & 0 & 0 & 2 & 6 & 2 & 5 & 2 & 9 & 5 & 1 & 3 & 1 & 2 & 8 & 3 & 2 & 2 & 2 \\
\hline Philonotis fontana (Hedw.) Brid. & 0 & 0 & 2 & 6 & 2 & 5 & 2 & 7 & 3 & 1 & 3 & 1 & 2 & 7 & 3 & 2 & 2 & 2 \\
\hline Platyhypnidium riparioides (Hedw.) Dixon & 0 & 0 & 2 & 4 & 0 & 5 & 2 & 4 & 5 & 1 & 3 & 1 & 2 & 5 & 2 & 2 & 2 & 2 \\
\hline Pohlia melanodon (Brid.) A.J. Shaw & 0 & 0 & 1 & 5 & 2 & 5 & 0 & 8 & 5 & 1 & 3 & 1 & 2 & 0 & 3 & 2 & 2 & 2 \\
\hline $\begin{array}{l}\text { Pohlia wahlenbergii (F. Weber \& D. Mohr) } \\
\text { A.L. Andrews }\end{array}$ & 0 & 0 & 1 & 5 & 2 & 5 & 0 & 8 & 5 & 1 & 3 & 1 & 2 & 0 & 3 & 2 & 2 & 2 \\
\hline $\begin{array}{l}\text { Tortula marginata (Bruch \& Schimp.) } \\
\text { Spruce }\end{array}$ & 0 & 0 & 2 & 6 & 2 & 4 & 2 & 3 & 4 & 0 & 1 & 1 & 2 & 8 & 0 & 2 & 1 & 2 \\
\hline
\end{tabular}

Table 6. Matrix table showing the character states (156 characters) for the 23 OTUs of aquatic and semi-aquatic mosses.

\begin{tabular}{|c|c|c|c|c|c|c|c|c|c|c|c|c|c|c|c|c|c|c|}
\hline Operational Taxonomic Unit (OTU) & 73 & 74 & 75 & 76 & 77 & 78 & 79 & 80 & 81 & 82 & 83 & 84 & 85 & 86 & 878 & 88 & 89 & 90 \\
\hline Barbula bolleana (Müll. Hal.) Broth. & 1 & 1 & 0 & 0 & 2 & 0 & 0 & 0 & 1 & 2 & 2 & 3 & 3 & 3 & 3 & 3 & 3 & 0 \\
\hline Bryum caespiticium Hedw. & 3 & 1 & 1 & 3 & 3 & 2 & 2 & 0 & 0 & 1 & 2 & 2 & 2 & 2 & 1 & 2 & 2 & 2 \\
\hline $\begin{array}{l}\text { Bryum pseudotriquetrum (Hedw.) P. } \\
\text { Gaertn., B. Mey \& Scherb. }\end{array}$ & 3 & 1 & 1 & 3 & 3 & 2 & 2 & 0 & 0 & 1 & 2 & 2 & 2 & 2 & 1 & 2 & 2 & 2 \\
\hline Cratoneuron filicinum (Hedw.) Spruce & 3 & 1 & 1 & 3 & 3 & 2 & 2 & 2 & 2 & 2 & 2 & 2 & 2 & 2 & 2 & 2 & 2 & 2 \\
\hline Didymodon tophaceus (Brid.) Lisa & 1 & 0 & 1 & 3 & 2 & 2 & 1 & 0 & 0 & 0 & 1 & 2 & 2 & 2 & 2 & 2 & 2 & 1 \\
\hline $\begin{array}{l}\text { Eucladium verticillatum (Brid.) Bruch \& } \\
\text { Schimp. }\end{array}$ & 3 & 1 & 0 & 3 & 2 & 1 & 2 & 0 & 0 & 2 & 2 & 2 & 2 & 2 & 2 & 2 & 2 & 2 \\
\hline Eurhynchium speciosum (Brid.) Jur. & 3 & 1 & 1 & 3 & 3 & 2 & 2 & 2 & 0 & 2 & 2 & 2 & 2 & 2 & 2 & 2 & 2 & 2 \\
\hline $\begin{array}{l}\text { Eurhynchium hians (Hedw.) Sande Lac. } \\
\text { var. hians }\end{array}$ & 3 & 1 & 1 & 3 & 3 & 2 & 2 & 2 & 0 & 2 & 2 & 2 & 2 & 2 & 2 & 2 & 2 & 2 \\
\hline $\begin{array}{l}\text { Fissidens crassipes subsp. warnstorfii (M. } \\
\text { Fleisch.) Brugg.-Nann. }\end{array}$ & 3 & 1 & 1 & 3 & 3 & 2 & 2 & 2 & 2 & 2 & 2 & 2 & 2 & 2 & 2 & 2 & 2 & 2 \\
\hline Fissidens grandifrons Brid. & 3 & 1 & 1 & 3 & 3 & 2 & 2 & 2 & 2 & 2 & 2 & 2 & 2 & 2 & 2 & 2 & 2 & 2 \\
\hline Fontinalis antipyretica Hedw. & 0 & 1 & 1 & 3 & 3 & 2 & 2 & 2 & 2 & 2 & 2 & 2 & 2 & 2 & 2 & 2 & 2 & 2 \\
\hline Fontinalis duriaei Schimp. & 0 & 1 & 1 & 3 & 3 & 2 & 2 & 2 & 2 & 2 & 2 & 2 & 2 & 2 & 2 & 2 & 2 & 2 \\
\hline Gymnostomum calcareum Nees \& Hornsch. & 1 & 0 & 0 & 3 & 1 & 2 & 2 & 1 & 0 & 0 & 1 & 2 & 2 & 2 & 2 & 2 & 2 & 2 \\
\hline Hygroamblystegium tenax (Hedw.) Jenn. & 4 & 2 & 0 & 1 & 3 & 2 & 2 & 2 & 1 & 0 & 2 & 2 & 1 & 1 & 2 & 2 & 2 & 3 \\
\hline $\begin{array}{l}\text { Hymenostylium recurvirostrum (Hedw.) } \\
\text { Dixon }\end{array}$ & 3 & 1 & 1 & 3 & 3 & 2 & 2 & 2 & 2 & 2 & 2 & 2 & 2 & 2 & 2 & 2 & 2 & 2 \\
\hline Leptodictyum humile (P. Beauv.) Ochyra & 2 & 1 & 0 & 3 & 3 & 2 & 2 & 2 & 0 & 1 & 2 & 2 & 2 & 2 & 1 & 2 & 2 & 2 \\
\hline Leptodictyum riparium (Hedw.) Warnst. & 2 & 1 & 0 & 3 & 3 & 2 & 2 & 2 & 0 & 1 & 2 & 2 & 2 & 2 & 1 & 2 & 2 & 2 \\
\hline Palustriella commutata (Hedw.) Ochyra & 3 & 1 & 0 & 3 & 3 & 2 & 2 & 2 & 2 & 2 & 2 & 2 & 2 & 2 & 2 & 2 & 2 & 2 \\
\hline Philonotis fontana (Hedw.) Brid. & 3 & 1 & 0 & 3 & 3 & 2 & 2 & 0 & 0 & 2 & 2 & 2 & 2 & 2 & 2 & 2 & 2 & 2 \\
\hline Platyhypnidium riparioides (Hedw.) Dixon & 3 & 1 & 0 & 3 & 3 & 2 & 2 & 2 & 0 & 2 & 2 & 2 & 2 & 2 & 1 & 1 & 2 & 2 \\
\hline Pohlia melanodon (Brid.) A.J. Shaw & 3 & 1 & 0 & 3 & 3 & 2 & 2 & 0 & 0 & 2 & 2 & 2 & 2 & 2 & 2 & 2 & 1 & 2 \\
\hline $\begin{array}{l}\text { Pohlia wahlenbergii (F. Weber \& D. Mohr) } \\
\text { A.L. Andrews }\end{array}$ & 3 & 1 & 0 & 3 & 3 & 2 & 2 & 0 & 0 & 2 & 2 & 2 & 2 & 2 & 2 & 2 & 1 & 2 \\
\hline $\begin{array}{l}\text { Tortula marginata (Bruch \& Schimp.) } \\
\text { Spruce }\end{array}$ & 1 & 1 & 0 & 2 & 1 & 2 & 2 & 0 & 0 & 2 & 2 & 1 & 2 & 2 & 2 & 2 & 2 & 2 \\
\hline
\end{tabular}


Table 7. Matrix table showing the character states (156 characters) for the 23 OTUs of aquatic and semi-aquatic mosses.

\begin{tabular}{|c|c|c|c|c|c|c|c|c|c|c|c|c|c|c|c|}
\hline Operational Taxonomic Unit (OTU) & 91 & 92 & 93 & 94 & 95 & 96 & 97 & 98 & 99 & 100 & 101 & 102 & 103 & 1041 & 105 \\
\hline Barbula bolleana (Müll. Hal.) Broth. & 1 & 0 & 1 & 2 & 0 & 1 & 0 & 0 & 1 & 0 & 1 & 2 & 1 & 2 & 2 \\
\hline Bryum caespiticium Hedw. & 1 & 0 & 1 & 2 & 1 & 0 & 0 & 2 & 2 & 1 & 1 & 2 & 1 & 2 & 2 \\
\hline $\begin{array}{l}\text { Bryum pseudotriquetrum (Hedw.) P. } \\
\text { Gaertn., B. Mey \& Scherb. }\end{array}$ & 1 & 0 & 1 & 2 & 1 & 0 & 0 & 2 & 2 & 1 & 1 & 2 & 1 & 2 & 2 \\
\hline Cratoneuron filicinum (Hedw.) Spruce & 2 & 1 & 1 & 1 & 2 & 2 & 4 & 2 & 2 & 2 & 0 & 2 & 1 & 2 & 2 \\
\hline Didymodon tophaceus (Brid.) Lisa & 0 & 0 & 1 & 2 & 0 & 0 & 0 & 0 & 1 & 2 & 1 & 0 & 1 & 2 & 2 \\
\hline $\begin{array}{l}\text { Eucladium verticillatum (Brid.) Bruch \& } \\
\text { Schimp. }\end{array}$ & 1 & 0 & 1 & 2 & 4 & 0 & 0 & 2 & 2 & 2 & 1 & 2 & 1 & 2 & 2 \\
\hline Eurhynchium speciosum (Brid.) Jur. & 1 & 4 & 1 & 2 & 4 & 2 & 1 & 2 & 2 & 2 & 1 & 2 & 1 & 2 & 2 \\
\hline $\begin{array}{l}\text { Eurhynchium hians (Hedw.) Sande Lac. } \\
\text { var. hians }\end{array}$ & 1 & 4 & 1 & 2 & 4 & 2 & 1 & 2 & 2 & 2 & 1 & 2 & 1 & 2 & 2 \\
\hline $\begin{array}{l}\text { Fissidens crassipes subsp. warnstorfii (M. } \\
\text { Fleisch.) Brugg.-Nann. }\end{array}$ & 1 & 4 & 3 & 2 & 4 & 2 & 4 & 2 & 2 & 2 & 1 & 2 & 1 & 2 & 2 \\
\hline Fissidens grandifrons Brid. & 1 & 4 & 3 & 2 & 4 & 2 & 4 & 2 & 2 & 2 & 1 & 2 & 1 & 2 & 2 \\
\hline Fontinalis antipyretica Hedw. & 1 & 4 & 3 & 2 & 3 & 2 & 4 & 2 & 2 & 2 & 1 & 2 & 1 & 2 & 2 \\
\hline Fontinalis duriaei Schimp. & 1 & 4 & 3 & 2 & 3 & 2 & 4 & 2 & 2 & 2 & 1 & 2 & 1 & 2 & 2 \\
\hline Gymnostomum calcareum Nees \& Hornsch. & 1 & 0 & 1 & 2 & 3 & 1 & 0 & 0 & 1 & 0 & 1 & 1 & 0 & 0 & 2 \\
\hline Hygroamblystegium tenax (Hedw.) Jenn. & 1 & 4 & 1 & 2 & 3 & 2 & 1 & 2 & 2 & 2 & 1 & 2 & 1 & 2 & 2 \\
\hline $\begin{array}{l}\text { Hymenostylium recurvirostrum (Hedw.) } \\
\text { Dixon }\end{array}$ & 1 & 4 & 3 & 2 & 4 & 2 & 4 & 0 & 1 & 2 & 1 & 2 & 1 & 2 & 2 \\
\hline Leptodictyum humile (P. Beauv.) Ochyra & 1 & 3 & 1 & 2 & 4 & 2 & 2 & 2 & 2 & 2 & 1 & 2 & 1 & 2 & 2 \\
\hline Leptodictyum riparium (Hedw.) Warnst. & 1 & 3 & 1 & 2 & 4 & 2 & 3 & 2 & 2 & 2 & 1 & 2 & 1 & 2 & 2 \\
\hline Palustriella commutata (Hedw.) Ochyra & 1 & 1 & 2 & 2 & 2 & 2 & 4 & 2 & 2 & 2 & 1 & 2 & 1 & 2 & 2 \\
\hline Philonotis fontana (Hedw.) Brid. & 1 & 0 & 1 & 2 & 3 & 0 & 0 & 2 & 2 & 2 & 1 & 2 & 1 & 2 & 1 \\
\hline Platyhypnidium riparioides (Hedw.) Dixon & 1 & 2 & 3 & 2 & 3 & 2 & 1 & 2 & 2 & 2 & 1 & 2 & 1 & 2 & 2 \\
\hline Poblia melanodon (Brid.) A.J. Shaw & 1 & 0 & 1 & 2 & 3 & 0 & 0 & 2 & 2 & 2 & 1 & 2 & 1 & 2 & 1 \\
\hline $\begin{array}{l}\text { Pohlia wablenbergii (F. Weber \& D. Mohr) } \\
\text { A.L. Andrews }\end{array}$ & 1 & 0 & 1 & 2 & 3 & 0 & 0 & 2 & 2 & 2 & 1 & 2 & 1 & 2 & 1 \\
\hline $\begin{array}{l}\text { Tortula marginata (Bruch \& Schimp.) } \\
\text { Spruce }\end{array}$ & 1 & 0 & 1 & 2 & 3 & 0 & 0 & 2 & 2 & 2 & 1 & 2 & 1 & 2 & 2 \\
\hline
\end{tabular}

Table 8. Matrix table showing the character states (156 characters) for the 23 OTUs of aquatic and semi-aquatic mosses.

\begin{tabular}{lccccccccccccccccc}
\hline \multicolumn{1}{c}{ Operational Taxonomic Unit (OTU) } & 106 & 107 & 108 & 109 & 110 & 111 & 112 & 113 & 114 & 115 & 116 & 117 & 118 & 119 & 120 \\
\hline $\begin{array}{l}\text { Barbula bolleana (Müll. Hal.) Broth. } \\
\text { Bryum caespiticium Hedw. }\end{array}$ & 0 & 0 & 0 & 0 & 0 & 0 & 0 & 0 & 0 & 1 & 1 & 1 & 2 & 2 & 0 \\
$\begin{array}{l}\text { Bryum pseudotriquetrum (Hedw.) P. Gaertn., } \\
\text { B. Mey \& Scherb. }\end{array}$ & 0 & 0 & 1 & 1 & 1 & 0 & 0 & 1 & 1 & 2 & 1 & 0 & 0 & 1 & 2 & 1 \\
$\begin{array}{l}\text { Cratoneuron filicinum (Hedw.) Spruce } \\
\text { Didymodon tophaceus (Brid.) Lisa }\end{array}$ & 0 & 2 & 2 & 2 & 0 & 0 & 6 & 1 & 1 & 2 & 1 & 1 & 2 & 2 & 1 \\
$\begin{array}{l}\text { Eucladium verticillatum (Brid.) Bruch \& } \\
\text { Schimp. }\end{array}$ & 0 & 0 & 0 & 0 & 0 & 0 & 0 & 0 & 1 & 1 & 1 & 2 & 1 & 0 & 0 \\
$\begin{array}{l}\text { Eurhynchium speciosum (Brid.) Jur. } \\
\text { Eurhynchium hians (Hedw.) Sande Lac. var. }\end{array}$ & 3 & 2 & 2 & 2 & 2 & 2 & 0 & 2 & 6 & 1 & 2 & 1 & 1 & 1 & 2 & 2 & 1 \\
hians & 3 & 2 & 0 & 2 & 2 & 1 & 2 & 2 & 0 & 1 & 2 & 2 & 1 \\
\hline
\end{tabular}


Table 8. Continued

\begin{tabular}{|c|c|c|c|c|c|c|c|c|c|c|c|c|c|c|c|}
\hline Operational Taxonomic Unit (OTU) & 106 & 107 & 108 & 109 & 110 & 111 & 112 & 113 & 114 & 115 & 116 & 117 & 118 & 119 & 120 \\
\hline $\begin{array}{l}\text { Fissidens crassipes subsp. warnstorfii (M. } \\
\text { Fleisch.) Brugg.-Nann. }\end{array}$ & 0 & 2 & 2 & 2 & 1 & 2 & 6 & 1 & 2 & 2 & 1 & 1 & 2 & 2 & 1 \\
\hline Fissidens grandifrons Brid. & 0 & 2 & 2 & 2 & 1 & 2 & 6 & 1 & 2 & 2 & 1 & 1 & 2 & 2 & 1 \\
\hline Fontinalis antipyretica Hedw. & 0 & 2 & 2 & 2 & 1 & 2 & 6 & 1 & 2 & 2 & 1 & 1 & 2 & 2 & 1 \\
\hline Fontinalis duriaei Schimp. & 0 & 2 & 2 & 2 & 1 & 2 & 6 & 1 & 2 & 2 & 1 & 1 & 2 & 2 & 1 \\
\hline Gymnostomum calcareum Nees \& Hornsch. & 0 & 0 & 1 & 0 & 0 & 0 & 0 & 1 & 2 & 1 & 1 & 0 & 2 & 2 & 0 \\
\hline Hygroamblystegium tenax (Hedw.) Jenn. & 3 & 2 & 2 & 2 & 0 & 0 & 6 & 1 & 2 & 1 & 1 & 1 & 2 & 2 & 1 \\
\hline $\begin{array}{l}\text { Hymenostylium recurvirostrum (Hedw.) } \\
\text { Dixon }\end{array}$ & 3 & 2 & 2 & 2 & 1 & 2 & 6 & 1 & 2 & 2 & 1 & 1 & 2 & 2 & 1 \\
\hline Leptodictyum humile (P. Beauv.) Ochyra & 3 & 2 & 2 & 2 & 0 & 0 & 6 & 1 & 2 & 1 & 1 & 1 & 2 & 2 & 1 \\
\hline Leptodictyum riparium (Hedw.) Warnst. & 3 & 2 & 2 & 2 & 0 & 0 & 6 & 1 & 2 & 1 & 1 & 1 & 2 & 2 & 1 \\
\hline Palustriella commutata (Hedw.) Ochyra & 0 & 2 & 2 & 2 & 0 & 0 & 6 & 1 & 2 & 2 & 1 & 1 & 2 & 2 & 1 \\
\hline Philonotis fontana (Hedw.) Brid. & 1 & 0 & 1 & 0 & 0 & 0 & 4 & 1 & 2 & 1 & 1 & 1 & 2 & 2 & 1 \\
\hline Platyhypnidium riparioides (Hedw.) Dixon & 3 & 2 & 2 & 2 & 0 & 0 & 6 & 1 & 2 & 1 & 1 & 1 & 2 & 2 & 1 \\
\hline Pohlia melanodon (Brid.) A.J. Shaw & 4 & 0 & 1 & 0 & 0 & 0 & 0 & 0 & 2 & 1 & 0 & 1 & 2 & 2 & 1 \\
\hline $\begin{array}{l}\text { Pohlia wahlenbergii (F. Weber \& D. Mohr) } \\
\text { A.L. Andrews }\end{array}$ & 4 & 0 & 1 & 0 & 0 & 0 & 2 & 0 & 2 & 1 & 0 & 1 & 2 & 2 & 1 \\
\hline $\begin{array}{l}\text { Tortula marginata (Bruch \& Schimp.) } \\
\text { Spruce }\end{array}$ & 1 & 0 & 1 & 0 & 0 & 0 & 6 & 1 & 1 & 1 & 1 & 0 & 2 & 1 & 0 \\
\hline
\end{tabular}

Table 9. Matrix table showing the character states (156 characters) for the 23 OTUs of aquatic and semi-aquatic mosses.

\begin{tabular}{|c|c|c|c|c|c|c|c|c|c|c|c|c|c|c|c|}
\hline Operational Taxonomic Unit (OTU) & 121 & 122 & 123 & 124 & 125 & 126 & 127 & 128 & 129 & 130 & 131 & 132 & 133 & 134 & 135 \\
\hline Barbula bolleana (Müll. Hal.) Broth. & 0 & 2 & 2 & 2 & 1 & 0 & 0 & 3 & 3 & 1 & 1 & 2 & 2 & 1 & 0 \\
\hline Bryum caespiticium Hedw. & 2 & 2 & 2 & 2 & 1 & 4 & 2 & 3 & 1 & 0 & 0 & 1 & 0 & 2 & 0 \\
\hline $\begin{array}{l}\text { Bryum pseudotriquetrum (Hedw.) P. Gaertn., } \\
\text { B. Mey \& Scherb. }\end{array}$ & 2 & 2 & 2 & 2 & 1 & 4 & 2 & 3 & 1 & 0 & 0 & 1 & 0 & 2 & 0 \\
\hline Cratoneuron filicinum (Hedw.) Spruce & 2 & 2 & 2 & 2 & 3 & 4 & 2 & 3 & 3 & 1 & 1 & 2 & 2 & 1 & 1 \\
\hline Didymodon tophaceus (Brid.) Lisa & 0 & 2 & 2 & 0 & 1 & 2 & 2 & 3 & 1 & 1 & 1 & 2 & 2 & 1 & 1 \\
\hline $\begin{array}{l}\text { Eucladium verticillatum (Brid.) Bruch \& } \\
\text { Schimp. }\end{array}$ & 2 & 2 & 2 & 2 & 3 & 4 & 2 & 3 & 3 & 1 & 1 & 2 & 2 & 2 & 1 \\
\hline Eurhynchium speciosum (Brid.) Jur. & 2 & 2 & 2 & 2 & 3 & 4 & 2 & 3 & 2 & 1 & 1 & 2 & 2 & 1 & 1 \\
\hline $\begin{array}{l}\text { Eurhynchium hians (Hedw.) Sande Lac. var. } \\
\text { hians }\end{array}$ & 2 & 2 & 2 & 2 & 3 & 4 & 2 & 3 & 2 & 1 & 1 & 2 & 2 & 1 & 1 \\
\hline $\begin{array}{l}\text { Fissidens crassipes subsp. warnstorfii (M. } \\
\text { Fleisch.) Brugg.-Nann. }\end{array}$ & 2 & 2 & 2 & 2 & 3 & 4 & 2 & 3 & 3 & 1 & 1 & 2 & 2 & 1 & 1 \\
\hline Fissidens grandifrons Brid. & 2 & 2 & 2 & 2 & 3 & 4 & 2 & 3 & 3 & 1 & 1 & 2 & 2 & 1 & 1 \\
\hline Fontinalis antipyretica Hedw. & 2 & 2 & 2 & 2 & 3 & 4 & 2 & 3 & 3 & 1 & 1 & 2 & 2 & 1 & 1 \\
\hline Fontinalis duriaei Schimp. & 2 & 2 & 2 & 2 & 3 & 4 & 2 & 3 & 3 & 1 & 1 & 2 & 2 & 1 & 1 \\
\hline Gymnostomum calcareum Nees \& Hornsch. & 2 & 1 & 1 & 2 & 1 & 1 & 2 & 3 & 3 & 1 & 1 & 2 & 2 & 1 & 1 \\
\hline Hygroamblystegium tenax (Hedw.) Jenn. & 2 & 2 & 2 & 2 & 3 & 4 & 2 & 3 & 3 & 1 & 1 & 2 & 2 & 1 & 1 \\
\hline $\begin{array}{l}\text { Hymenostylium recurvirostrum (Hedw.) } \\
\text { Dixon }\end{array}$ & 2 & 2 & 2 & 2 & 0 & 4 & 2 & 3 & 3 & 1 & 1 & 2 & 2 & 1 & 1 \\
\hline Leptodictyum humile (P. Beauv.) Ochyra & 2 & 2 & 2 & 2 & 3 & 2 & 2 & 0 & 3 & 1 & 1 & 2 & 2 & 0 & 1 \\
\hline Leptodictyum riparium (Hedw.) Warnst. & 2 & 2 & 2 & 2 & 3 & 2 & 2 & 0 & 3 & 1 & 1 & 2 & 2 & 0 & 1 \\
\hline
\end{tabular}


Table 9. Continued

\begin{tabular}{|c|c|c|c|c|c|c|c|c|c|c|c|c|c|c|c|}
\hline Operational Taxonomic Unit (OTU) & 121 & 122 & 123 & 124 & 125 & 126 & 127 & 128 & 129 & 130 & 131 & 132 & 133 & 134 & 135 \\
\hline Palustriella commutata (Hedw.) Ochyra & 2 & 2 & 2 & 2 & 3 & 4 & 2 & 3 & 3 & 1 & 1 & 2 & 2 & 1 & 1 \\
\hline Philonotis fontana (Hedw.) Brid. & 2 & 2 & 2 & 2 & 3 & 4 & 2 & 3 & 1 & 1 & 1 & 2 & 2 & 1 & 1 \\
\hline Platyhypnidium riparioides (Hedw.) Dixon & 2 & 2 & 2 & 2 & 3 & 4 & 2 & 3 & 3 & 1 & 1 & 2 & 2 & 1 & 1 \\
\hline Pohlia melanodon (Brid.) A.J. Shaw & 2 & 2 & 2 & 2 & 3 & 3 & 2 & 3 & 3 & 1 & 1 & 2 & 2 & 1 & 0 \\
\hline $\begin{array}{l}\text { Pohlia wahlenbergii (F. Weber \& D. Mohr) } \\
\text { A.L. Andrews }\end{array}$ & 2 & 2 & 2 & 2 & 3 & 3 & 2 & 3 & 3 & 1 & 1 & 2 & 2 & 1 & 0 \\
\hline $\begin{array}{l}\text { Tortula marginata (Bruch \& Schimp.) } \\
\text { Spruce }\end{array}$ & 2 & 0 & 2 & 0 & 1 & 4 & 1 & 2 & 3 & 1 & 1 & 2 & 2 & 1 & 1 \\
\hline
\end{tabular}

Table 10. Matrix table showing the character states (156 characters) for the 23 OTUs of aquatic and semi-aquatic mosses.

\begin{tabular}{|c|c|c|c|c|c|c|c|c|c|c|c|}
\hline Operational Taxonomic Unit (OTU) & 136 & 137 & 138 & 139 & 140 & 141 & 142 & 143 & 144 & 145 & 146 \\
\hline Barbula bolleana (Müll. Hal.) Broth. & 0 & 0 & 1 & 0 & 0 & 0 & 0 & 5 & 2 & 1 & 1 \\
\hline Bryum caespiticium Hedw. & 0 & 2 & 3 & 2 & 3 & 1 & 2 & 2 & 0 & 1 & 0 \\
\hline $\begin{array}{l}\text { Bryum pseudotriquetrum (Hedw.) P. Gaertn., B. Mey \& } \\
\text { Scherb. }\end{array}$ & 0 & 2 & 3 & 2 & 3 & 1 & 2 & 2 & 0 & 1 & 0 \\
\hline Cratoneuron filicinum (Hedw.) Spruce & 1 & 2 & 3 & 2 & 3 & 1 & 2 & 5 & 2 & 2 & 1 \\
\hline Didymodon tophaceus (Brid.) Lisa & 1 & 0 & 2 & 0 & 0 & 0 & 2 & 0 & 2 & 1 & 1 \\
\hline Eucladium verticillatum (Brid.) Bruch \& Schimp. & 1 & 2 & 3 & 2 & 1 & 1 & 2 & 2 & 1 & 1 & 1 \\
\hline Eurhynchium speciosum (Brid.) Jur. & 1 & 2 & 3 & 2 & 3 & 1 & 2 & 5 & 2 & 1 & 1 \\
\hline Eurhynchium hians (Hedw.) Sande Lac. var. hians & 1 & 2 & 3 & 2 & 3 & 1 & 2 & 5 & 2 & 1 & 1 \\
\hline $\begin{array}{l}\text { Fissidens crassipes subsp. warnstorfii (M. Fleisch.) Brugg.- } \\
\text { Nann. }\end{array}$ & 1 & 2 & 3 & 2 & 3 & 1 & 2 & 5 & 2 & 2 & 1 \\
\hline Fissidens grandifrons Brid. & 1 & 2 & 3 & 2 & 3 & 1 & 2 & 5 & 2 & 2 & 1 \\
\hline Fontinalis antipyretica Hedw. & 1 & 2 & 3 & 2 & 3 & 1 & 2 & 3 & 2 & 2 & 1 \\
\hline Fontinalis duriaei Schimp. & 1 & 2 & 3 & 2 & 3 & 1 & 2 & 3 & 2 & 2 & 1 \\
\hline Gymnostomum calcareum Nees \& Hornsch. & 1 & 0 & 2 & 2 & 2 & 1 & 2 & 2 & 2 & 1 & 1 \\
\hline Hygroamblystegium tenax (Hedw.) Jenn. & 1 & 2 & 3 & 2 & 3 & 1 & 2 & 5 & 2 & 2 & 1 \\
\hline Hymenostylium recurvirostrum (Hedw.) Dixon & 1 & 2 & 3 & 2 & 3 & 1 & 2 & 5 & 2 & 2 & 1 \\
\hline Leptodictyum humile (P. Beauv.) Ochyra & 1 & 2 & 3 & 2 & 3 & 1 & 2 & 0 & 2 & 1 & 1 \\
\hline Leptodictyum riparium (Hedw.) Warnst. & 1 & 2 & 3 & 2 & 3 & 1 & 2 & 0 & 2 & 1 & 1 \\
\hline Palustriella commutata (Hedw.) Ochyra & 1 & 2 & 3 & 2 & 3 & 1 & 2 & 5 & 2 & 2 & 1 \\
\hline Philonotis fontana (Hedw.) Brid. & 1 & 2 & 3 & 2 & 1 & 1 & 2 & 2 & 2 & 1 & 1 \\
\hline Platyhypnidium riparioides (Hedw.) Dixon & 1 & 2 & 3 & 2 & 3 & 1 & 2 & 5 & 2 & 1 & 1 \\
\hline Pohlia melanodon (Brid.) A.J. Shaw & 0 & 2 & 3 & 2 & 3 & 1 & 2 & 2 & 1 & 1 & 1 \\
\hline Pohlia wahlenbergii (F. Weber \& D. Mohr) A.L. Andrews & 0 & 2 & 3 & 2 & 3 & 1 & 2 & 2 & 1 & 1 & 1 \\
\hline Tortula marginata (Bruch \& Schimp.) Spruce & 1 & 2 & 3 & 2 & 1 & 1 & 2 & 2 & 2 & 1 & 1 \\
\hline
\end{tabular}


Table 11. Matrix table showing the character states (156 characters) for the 23 OTUs of aquatic and semi-aquatic mosses.

\begin{tabular}{|c|c|c|c|c|c|c|c|c|c|c|}
\hline Operational Taxonomic Unit (OTU) & 147 & 148 & 149 & 150 & 151 & 152 & 153 & 154 & 155 & 156 \\
\hline Barbula bolleana (Müll. Hal.) Broth. & 2 & 2 & 1 & 2 & 0 & 0 & 0 & 1 & 2 & 1 \\
\hline Bryum caespiticium Hedw. & 1 & 1 & 1 & 2 & 0 & 2 & 2 & 1 & 2 & 1 \\
\hline $\begin{array}{l}\text { Bryum pseudotriquetrum (Hedw.) P. Gaertn., B. Mey \& } \\
\text { Scherb. }\end{array}$ & 1 & 1 & 1 & 2 & 0 & 2 & 2 & 1 & 2 & 1 \\
\hline Cratoneuron filicinum (Hedw.) Spruce & 2 & 2 & 1 & 2 & 1 & 2 & 2 & 1 & 2 & 1 \\
\hline Didymodon tophaceus (Brid.) Lisa & 2 & 2 & 1 & 2 & 0 & 1 & 1 & 1 & 2 & 1 \\
\hline Eucladium verticillatum (Brid.) Bruch \& Schimp. & 2 & 2 & 1 & 2 & 0 & 2 & 2 & 1 & 2 & 1 \\
\hline Eurhynchium speciosum (Brid.) Jur. & 2 & 2 & 1 & 2 & 1 & 2 & 2 & 0 & 2 & 1 \\
\hline Eurhynchium hians (Hedw.) Sande Lac. var. hians & 2 & 2 & 1 & 2 & 1 & 2 & 2 & 0 & 2 & 1 \\
\hline $\begin{array}{l}\text { Fissidens crassipes subsp. warnstorfii (M. Fleisch.) Brugg.- } \\
\text { Nann. }\end{array}$ & 2 & 2 & 1 & 2 & 1 & 2 & 2 & 1 & 2 & 1 \\
\hline Fissidens grandifrons Brid. & 2 & 2 & 1 & 2 & 1 & 2 & 2 & 1 & 2 & 1 \\
\hline Fontinalis antipyretica Hedw. & 2 & 2 & 1 & 2 & 1 & 2 & 2 & 1 & 2 & 1 \\
\hline Fontinalis duriaei Schimp. & 2 & 2 & 1 & 2 & 1 & 2 & 2 & 1 & 2 & 1 \\
\hline Gymnostomum calcareum Nees \& Hornsch. & 2 & 2 & 1 & 2 & 0 & 2 & 2 & 1 & 2 & 1 \\
\hline Hygroamblystegium tenax (Hedw.) Jenn. & 1 & 2 & 2 & 1 & 2 & 2 & 2 & 1 & 2 & 1 \\
\hline Hymenostylium recurvirostrum (Hedw.) Dixon & 2 & 2 & 1 & 2 & 1 & 2 & 2 & 1 & 2 & 1 \\
\hline Leptodictyum humile (P. Beauv.) Ochyra & 2 & 2 & 0 & 2 & 1 & 2 & 2 & 0 & 0 & 0 \\
\hline Leptodictyum riparium (Hedw.) Warnst. & 2 & 2 & 0 & 2 & 1 & 2 & 2 & 0 & 0 & 0 \\
\hline Palustriella commutata (Hedw.) Ochyra & 2 & 2 & 1 & 2 & 1 & 2 & 2 & 1 & 2 & 1 \\
\hline Philonotis fontana (Hedw.) Brid. & 2 & 2 & 1 & 2 & 0 & 2 & 2 & 1 & 2 & 1 \\
\hline Platyhypnidium riparioides (Hedw.) Dixon & 2 & 2 & 1 & 2 & 1 & 2 & 2 & 0 & 2 & 1 \\
\hline Pohlia melanodon (Brid.) A.J. Shaw & 2 & 2 & 1 & 2 & 0 & 2 & 2 & 1 & 2 & 1 \\
\hline Pohlia wahlenbergii (F. Weber \& D. Mohr) A.L. Andrews & 2 & 2 & 1 & 2 & 0 & 2 & 2 & 1 & 2 & 1 \\
\hline Tortula marginata (Bruch \& Schimp.) Spruce & 2 & 2 & 1 & 1 & 0 & 2 & 2 & 1 & 2 & 1 \\
\hline
\end{tabular}

The output of the analysis is presented in phenogram (Figure 1). In the first, second and third node, the linkage distance value is 1.0000 for Bryum caespiticium and Bryum pseudotriquetrum, Eurhynchium speciosum and Eurhynchium hians var. hians; and, Leptodictyum humile and Leptodictyum riparium, respectively. The distance linkage between Pohlia melanodon and Pohlia wahlenbergii is 2.0000 (node 4). As for node 5, the value is 3.0000 between Fontinalis antipyretica and Fontinalis duriaei. Two different genera of Cratoneuron filicinum and Palustriella commutata showed the value of 3.7417 in node 6. Fissidens crassipes subsp. warnstorfii and Fissidens grandifrons in the seventh node are distantly valued 4.0000 .

At the eighth node (6.4807), Cratoneuron filicinum, Palustriella commutata, Fissidens crassipes subsp. warnstorfii and Fissidens grandifrons were linkaged. Next, Cratoneuron filicinum, Palustriella commutata, Fissidens crassipes subsp. warnstorfi, Fissidens grandifrons and Hymenostylium recurvirostrum were clustered under node 9 with linkage distance value of 8.0000. At the tenth node, Cratoneuron filicinum, Palustriella commutata, Fissidens crassipes subsp. warnstorfii, Fissidens grandifrons, Hymenostylium recurvirostrum, Fontinalis antipyretica and Fontinalis duriaei were distantly measured with value of 9.6954 . 
With distance linkage value of 10.2956, three species of Leptodictyum humile, Leptodictyum riparium and Platyhypnidium riparioides were linkaged under node 11 . Next, Eurhynchium speciosum, Eurhynchium hians var. hians, Leptodictyum humile, Leptodictyum riparium and Platyhypnidium riparioides were analyzed to have distance linkage value of 10.3923 (twelfth node). Under node 13, there are Eurhynchium speciosum, Eurhynchium hians var. hians, Leptodictyum humile, Leptodictyum riparium, Platyhypnidium riparioides and Philonotis Fontana (11.3137). Cratoneuron filicinum, Palustriella commutata, Fissidens crassipes subsp. warnstorfi, Fissidens grandifrons, Hymenostylium recurvirostrum, Fontinalis antipyretica, Fontinalis duriaei, Eurhynchium speciosum, Eurhynchium hians var. hians, Leptodictyum humile, Leptodictyum riparium, Platyhypnidium riparioides and Philonotis Fontana are under one cluster group (node 14 and distance linkage equals to 11.5326).

Under node 15, Didymodon tophaceus and Gymnostomum calcareum were found with 11.7898 value. For the sixteenth node, Cratoneuron filicinum, Palustriella commutata, Fissidens crassipes subsp. warnstorfii, Fissidens grandifrons, Hymenostylium recurvirostrum, Fontinalis antipyretica, Fontinalis duriaei, Eurhynchium speciosum, Eurhynchium hians var. hians, Leptodictyum humile, Leptodictyum riparium, Platyhypnidium riparioides, Philonotis Fontana and Hygroamblystegium tenax were having distance value of 11.8743. With linkage distance value of 12.0831, Didymodon tophaceus, Gymnostomum calcareum and Eucladium verticillatum were grouped under node 17.

Node 18 showed the combination between node 16 and 17 with 12.4097 . Distance linkage value of 12.4499 grouped all OTUs under node 18 and node 4 to become node 19. As for node 20, the combination is between node 19 and Tortula marginata (12.5300). Barbula bolleana and node 20 (12.8452) formed node 21. The distance linkage value for all OTUs is 12.8564 .

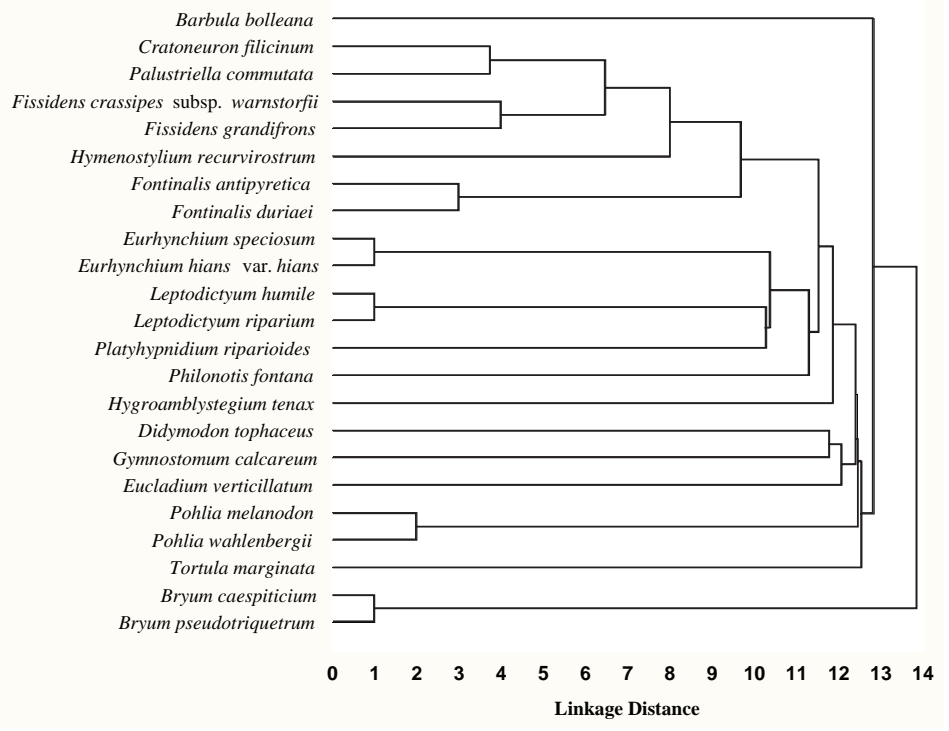

Figure 1. Dendogram showing the single linkage (nearest neighbours) clustering relationship based on Euclidean Distance among the 23 species of mosses 
According to the principal component and classification analysis, the quality of representation value is $100 \%$ or most reliable. The first three components explained $75.1064 \%$ of the variation with $56.0485 \%$ (PC1), $11.7346 \%$ (PC2) and $7.3233 \%$ (PC3) respectively (Table 12). Components with eigenvalues lower than 1 were eliminated and not significant statistically. For PC1, the main variables are from the vegetative parts (plant and leaf) and major morphometric characters are numbered 3, 8, 9, 26, 27, 33 (negative loading), 51 (negative loading), 54 (negative loading), 55, 56, 58 (negative loading), 60 (negative loading), 63 (negative loading), 68 (negative loading) and 143 (negative loading). Less important on the reproductive part (capsule): 110, 112 (negative loading) and 126 (negative loading). PC2 showed the major variable is alar cells of leaf (92). The focal part is on the vegetative component of the bryophyte. Factor loading scores for PC3 were less correlated to the variables (characters) as compared to PC1 and PC2 . Any factor score lower than 5.0000 is considered insignificant and eliminated from the factor loading tables.

Table 12. Taxometric variables for the first three principal components

\begin{tabular}{cccc}
\hline Component & Eigenvalue & \% Total Variance & Cumulative \% \\
\hline 1 & 12.89116 & 56.04853 & 56.0485 \\
2 & 2.69895 & 11.73459 & 67.7831 \\
3 & 1.68436 & 7.32332 & 75.1064 \\
\hline
\end{tabular}

Figure 2. shows that mosses are skewed obviously to the negative side for PC1. PC1 grouped species obviously into three groups (i, j, o, d, r, n, k, l, p, q, h and $\mathrm{g} ; \mathrm{s}, \mathrm{v}, \mathrm{u}$ and $\mathrm{f}$; and $\mathrm{e}, \mathrm{b}$ and $\mathrm{c}$ ) and 4 identical individual species ( $\mathrm{t}, \mathrm{w}, \mathrm{m}$ and a). As for PC2 (Figure 2), 2 groups were segregated into the positive (i, j, o, d, r, n, $\mathrm{k}, \mathrm{l}, \mathrm{p}, \mathrm{q}, \mathrm{h}$ and $\mathrm{g}$ ) and negative ( $, \mathrm{v}, \mathrm{u}, \mathrm{f}, \mathrm{m}, \mathrm{a}, \mathrm{e}, \mathrm{b}$ and $\mathrm{c}$ ) sides; and 2 individual species near to the intermediary part ( $\mathrm{t}$ and $\mathrm{w})$.

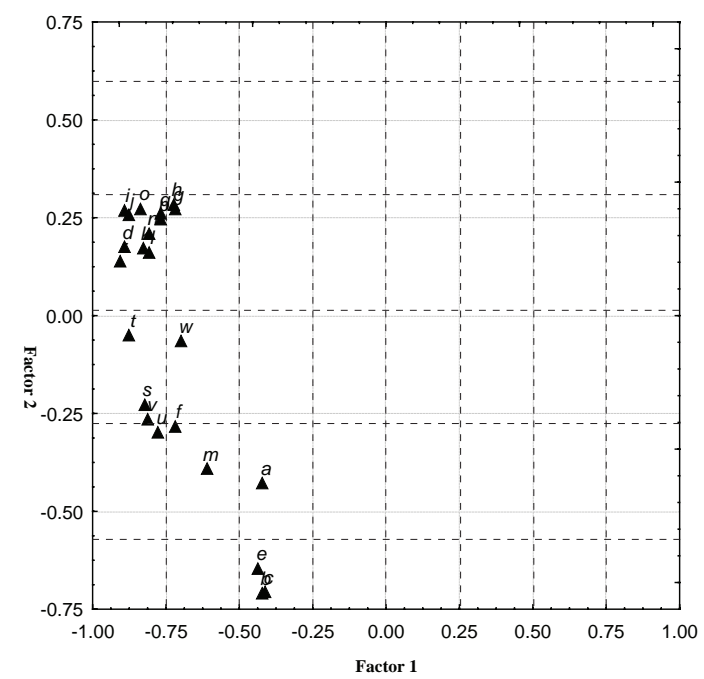

Figure 2. Scatter diagram between PC1 and PC2 from principal component analysis of 23 species of aquatic and semi-aquatic mosses using 156 characters 
In Figure 3, PC3 grouped OTUs into one positive group of h, g, b, c, p, q, t, n and $\mathrm{w}$; negative group of $\mathrm{m}, \mathrm{e}, \mathrm{a}, \mathrm{k}, \mathrm{l}, \mathrm{r}, \mathrm{i}, \mathrm{d}, \mathrm{j}, \mathrm{k}, \mathrm{l}, \mathrm{o}, \mathrm{v}$ and $\mathrm{u}$; one species under intermediary line (f); and one species near to intermediary line (s). PC1 (Figure 3) segregated the individuals inconspicuously. Basically, individual species grouped under intermediary area is sharing characters from positive and negative sides.

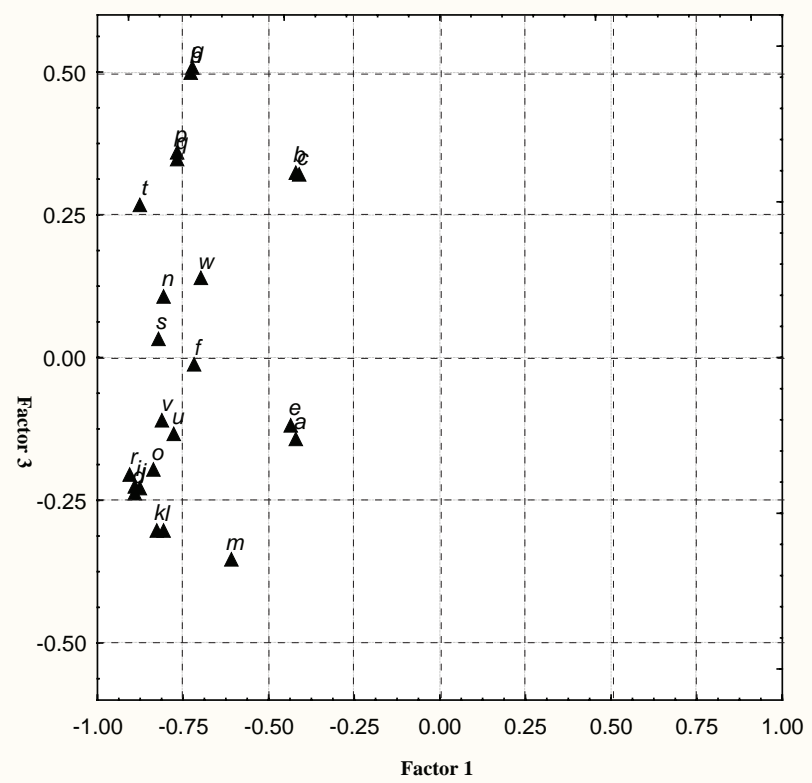

Figure 3. Scatter diagram between PC1 and PC3 from principal component analysis of 23 species of aquatic and semi-aquatic mosses using 156 characters

For cluster analysis, the algorithm chosen was hierarchical (aggromerative) (Tipirdamaz et al. 2006). This is because the main objective of this study is to group OTUs from smaller clusters into a larger groups (polythetic) (Stuessy 1990). The end result is to divide clustered groups for efficient aquatic and semi- aquatic bryodiversity management. The amalgation rule for analysis was single linkage (nearest neighbour) as the purpose to study the species relationship among OTUs and the measurement for distance between species was based on Euclidean distance. Euclidean distance is the most common and easy to interpret (Statistica 6.0, 2001). In this analysis, numbers of variables, cases and subcases analyzed were massive. Indirectly, biases and standard deviations were minimized. As the result, the reliability of the output is more than $96 \%$.

On the other hand, clustering bryodiversity into few manageable units are very crucial and cost-effective. The relationship between a cluster of mosses reflects the generic, familial or higher taxonomic similarity. Genetically, they are sharing a closer gene pool (genotypes) and morphologically, the phenotypes are significant characters for identification and serving the ecosystem. Mosses are natural bioindicator for water quality, soil erosion controller and filtering the wastewater naturally (Ando and Matsuo 1984; 
Frahm 1996; Welch 1948; Conrad 1935; Whitehouse and McAllister 1954; Ando 1957; Grout 1912; Coupal and Lalancette 1976). Thus, this approach can help bryodiversity managers to conserve the aquatic and semi-aquatic mosses in a collective way. In a simple manner, we efficiently manage all the clusters of mosses equally. Equality helps in balancing the habitat (ecosystem) for the benefits of human beings. Ironically, wrong management strategy can be bias to certain species, the other species will be neglected and the ecosystem will not be served naturally.

From the dendogram (Figure 1), there are 22 nodes. Thus, management strategy can be based on the nodes in the phenogram. For node 10, one management cluster can be formed from few subclusters which consists of Cratoneuron filicinum, Palustriella commutata, Fissidens crassipes subsp. warnstorfi, Fissidens grandifrons, Hymenostylium recurvirostrum, Fontinalis antipyretica and Fontinalis duriaei. Subclusters of node 13 (Eurhynchium speciosum, Eurhynchium hians var. hians, Leptodictyum humile, Leptodictyum riparium, Platyhypnidium riparioides and Philonotis Fontana), node 18 (Didymodon tophaceus, Gymnostomum calcareum, Hygroamblystegium tenax and Eucladium verticillatum), node 20 (Tortula marginata, Pohlia wahlenbergii and Pohlia melanodon) and node 22 (Bryum caespiticium, Bryum pseudotriquetrum and Barbula bolleana). In short, five management units of bryodiversity are proposed for management.

Under principal component analysis (PCA), management of clustered groups are strengthened (Tipirdamaz et al. 2006). Based on Statistica 6.0 (2001), PCA is reducing the numbers of variables and transform important variables into numbers of principal component. This is beneficial in management, where precise group of identifiable characters (in this context) are known for management and conservation. Furthermore, PCA is a very cost-effective tool for biodiversity management.

In cluster analysis, bryodiversity management is based on hierachical clustered manageable unit and PCA is based on group of related characters that forms one factor. In this case, we have three principal components. In the first principal component (Figure 2 ), we have three distinct groups and four independent OTUs (can form two minor groups). Thus, 5 managable units can be formed. All OTUs were skewed to the negative side. Statistically, it signifies all the OTUs were likely characterized differently from the common character states. This is very similar to the numbers of manageable units derived from cluster analysis, but with distinct species combination. As for the second component, 3 managable units were formed. It consists of a positive group that agrees with most of the common character states, a negative group that complies likely to the opposite character states and two intermediary individuals (skewed a bit to the negative side) where sharing both common and uncommon (more) character states. In Figure 3, three manageable units were observed: one positive-skewed group, one negative-skewed group and one individual in the intermediary line.

Comparing both taxometric classifications, cluster analysis is useful in hierachically linked OTUs for relationship-based management approach. All characters have the same weight and will be used totally. As for PCA, it groups OTUs on the scatter plot that refers to the group of important characters (principal component). Thus, only critical characters are used for efficient management. Relatively, both approaches to bryodiversity management are highly appreciated. Only through cluster analysis, the linkage distance will be known and important for future populational references. This means that populations are 
evolving and further revisions will further change the taxonomic structure. For instance, PCA does not show this feature. In a nutshell, both approaches are supplementing each ones. Both combinations will help in solving managerial dilemma and problems.

\section{CONCLUSION}

Bryodiversity in the Mediterrean area of Spain is relatively lower (23 species of aquatic and semi-aquatic mosses) as compared to the 46 species recorded in the Tropical region of Sabah, Malaysia.Bryoflora conservation cum management have to be taken place. This is critical as the bryophytes are naturally serving the ecosystems continually and sustainably. The studied mosses were phenetically related and could be divided into 5 cluster groups through cluster analysis. The clustered group can be managed as a manageable unit. The rationale is that no single population will be overmanaged or neglected; and equal conservational plan to be implemented among the phenetically related units.

The manipulation of Principal Component Analysis (PCA) in this study reduced the least important characters used for management. The output produced three components with each group contain numbers of vital characters within. This is costeffective for bryodiversity managers. This analysis allowed managers to identify, manage and conserve populations based on the components. From this study, output from cluster analysis will be an alternative to the results produced from the PCA. Nevertheless, both outputs are highly reliable and ready to be used for management. In a nutshell, it is more meaningful to conserve natural environmental regulator rather than creating man-made mitigator.

\section{ACKNOWLEDGMENTS}

The grant for this project was from European Commission (EC) under the Erasmus Mundus Programme (EMP). The author would like to express his thankfulness to Mr. Reymond P. Echavaria III for his comments on the statistical analyses.

\section{REFERENCES}

Aguilar D., F.X.Aviles, E. Querol and M.J.E. Sternberg. 2004. Analysis of Phenetic Trees Based on Metabolic Capabilities across the Three Domain of Life. Journal of Molecular Biology 340: 491-512.

Ando H. 1957. Notes on Useful Bryophytes. Bulletin of the Biology Society of Hiroshima University 7(2): 23-26.

Ando H. and A. Matsuo. 1984. Applied Bryology. Advances in Bryology 2: 133-224.

Conrad H.S. 1935. Mosses and Soil Erosion. Iowa State College Journal of Science 9: 347-351.

Coupal B. and J.M. Lalancette. 1976. The Treatment of Waste Water with Peat Moss. Water Research 10: 1071-1076. 
Taxometrics classification of aquatic and semi-aquatic mosses - M.J. Loo et al.

Ferguson M. E., N. Maxted, M.V. Slageren and L.D. Robertson. 2000. A Re-assessment of the Taxonomy of Lens Mills (Leguminosae, Papilionoideae, Vicieae). Botanical Journal of Linnean Society 133: 41-59.

Frahm J.P. 2003. Manual of Tropical Bryology. Tropical Bryology 23: 1-197.

Frahm J.P., W. Frey, H. Kurschner and M. Menzel. 1996. Mosses and Liverworts of Mount Kinabalu. Natural History Publications, Kota Kinabalu.

Grout A.J. 1912. Mosses as Factor in Land Conservation. Bryologist 15: 37.

Holmes J.M.C. 1998 Phenetic Relationships among some free-living siphonostomatoid copepods from southwest Ireland, and the description of Glannapontius maculates gen. et sp. nov. Journal of Marine Systems 15: 229-241.

Kim C, H. Shin and H. Choi . 2003. A Phenetic Analysis of Typha in Korea and far east Russia. Aquatic Botany 75: 33-43.

Komosinki M., G. Koczyk and M. Kubiak. 2001. On Estimating Similarity of Artificial and Real Organisms. Theory in Biosciences 120: 271-286.

Luna Cavazos M., M. Jiao and R. Bye 2000. Phenetic Analysis of Datura section Dutra (Solanaceae) in Mexico. Botanical Journal of Linnean Society 133: 493-507.

Mazak J. H. and C.P. Groves. 2006. A taxonomic Revision of the Tigers (Panthera tigris) of Southeast Asia. Mammalian Biology 71: 268-287.

McNulty K. P. 2004. A geometric Morphometric Assessment of Hominoid Crania: Conservative African Apes and their Liberal Implications. Annals of Anaomy 186; 429-433.

Madeira P.T., T.K. Van and T.D. Center T. D. 1999. Integration of Five Southeast Asian Accessions into the World-wide Phenetic Relationships of Hydrilla verticillata as elucidated by random amplified polymorphic DNA Analysis. Aquatic Botany 63: 161-167.

Raffield B. T. and F.G. Bingham . 1994. Business Marketing Management. South-Western Pub, USA.

Romero A., M. Luna Cavazos , E. García and M.F. Passini. 2000. Phenetic Analysis of the Mexican Midland Pinyon Pines, Pinus cembroides and Pinus johannis. Journal of Linnean Society 133: 181-194.

Scotland R.W. and M.A. Carine . 2000. Classification or Phylogenetic Estimates? Cladistics 16: 411-419.

Sharma I. K., D.L. Jones and P.I. Forster. 2004. Genetic Differentiation and Phenetic Relatedness among Seven species of the Macrozamia plurinervia complex (Zamiaceae). Biochemical Systematics and Ecology 32: 313-327.

Smith A.J.E. 1978. Cytogenetics, Biosystematics and Evolution in the Bryophyta. Advances in Botanical Research 6: 195-276.

Statistica 6.0. 2001. Help Contents and Index. Statsoft, Inc., USA.

Stotler B.C. and R.E. Stotler. 2000. Morphology and Classification of the Marchantiopsida. In: Shaw, A.J. and Goffinet, B. (Ed.). Bryophyte Biology. Cambridge University Press, United Kingdom.

Stuessy T.F. 1990. Plant Taxonomy. The Systematic Evaluation, of Comparative Data. Columbia University Press, New York. 
Tipirdamaz R., D. Gagneul , C. Duhaze, A. Aïnouche, C. Monnier, D. Ozkum and F. Larher. 2006. Clustering of Halophytes from an Inland Salt Marshes in Turkey According to their Ability to Accumulate Sodium and Nitrogenous Osmolytes. Environmental and Experimental Botany 57: 139-153.

Tsai C. C., S.C. Huang, P.L. Huang, Y.S. Chen and C.H. Chou. 2002. Phenetic Relationship and Identification of Subtribe Oncidiinae Genotypes by Random Amplified Polymorphic DNA (RAPD) Markers. Scientia Horticulturae 96: 303-312.

Welch W. H. 1948. Mosses and Their Uses. Proeedings of the Indiana Academic of Science 58: 31-46.

Whitehouse E. and F. McAllister. 1954. The Mosses of Texas. A Catalogue with annotations. Bryologist 57: 63-146.

Yamagishi M., S. Matsumoto S., A. Nakatsuka and H. Itamura . 2005. Identification of Persimmon (Dyopyros kaki) Cultivars and Phenetic Relationships between Diopyros species by more Effective RAPD Analysis. Scientia Horticulturae 105: 283-290. 